\title{
Performance of Building with Basements Under Seismic Excitation Considering Soil Structure Interaction
}

\author{
Abdullah Lala, Toshif Patel, Ravi Karkar, Jigar Sevalia
}

\begin{abstract}
In modern construction, there is a trend to go deeper below the grade level in terms of basements which can be utilized for parking, shopping malls or a combination of both. In such cases, dynamic soil properties have a significant effect of activating dynamic soil structure interaction phenomenon during earthquake. Here in present study an effort is made to study the behavior of a building by varying five and three number of basements considering dynamic soil structure interaction. Issues like influence zone to be considered for dynamic soil structure interaction, behavior of building with basements under different water level conditions for two different types of layered soil and their comparison with fixed based structure for a real-life structure is dealt with. It is observed that dynamic soil structure interaction can significantly change the behavior and also the failure pattern of the building and hence it is recommended to perform dynamic soil structure interaction for building with multiple basements.
\end{abstract}

Keywords: Basements, Dynamic soil structure interaction, layered soil, multiple underground stories, Nonlinear direct integration time history.

\section{INTRODUCTION}

Under the Earthquake, the same structure having same structural properties when founded on different soil behave differently. When the structure is founded on rock, the motion of the rock is constrained by the extreme high stiffness of rock which allows the seismic waves to travel faster. However, when the same structure is founded on the soft soil, the seismic waves slows down and its amplitude gets bigger thereby causing amplification of ground motion. Due to this amplification, the motion at the base of the structure diverges from the free field motion, due to the inability of the foundation to adapt to the free field deformation. Under this situation, the response of soil influences the response of structure and vice versa. This

Manuscript received on January 10, 2021.

Revised Manuscript received on January 20, 2021.

Manuscript published on January 30, 2021.

* Correspondence Author

Abdullah Lala*, Department of Civil Engineering, Sarvajanik College of Engineering and Technology Surat, India. Email: lalaa315@gmail.com

Toshif Patel, Engineer, Varjlal V. Ambaliya Structural Engineer and Consultant, Surat, India. Email: ptosif72@gmail.com

Ravi Karkar, Engineer, Varjlal V. Ambaliya Structural Engineer and Consultant, Surat, India. Email: ravikarkar18@gmail.com

Dr. Jigar Sevalia, Professor \& Head, Department of Civil Engineering, Sarvajanik college of Engineering and Technology Surat, India. Email: jigar.sevalia@scet.ac.in

(c) The Authors. Published by Blue Eyes Intelligence Engineering and Sciences Publication (BEIESP). This is an open access article under the CC BY-NC-ND license (http://creativecommons.org/licenses/by-nc-nd/4.0/) phenomenon is generally termed as Dynamic Soil Structure Interaction. Soil structure interaction may occur in two forms namely inertial and kinematic interaction. The interaction in which dynamic response of structure induces deformation of the supporting soil is known as Inertial Interaction while the interaction in which the stiffer structure does not deforms as that of the soil is termed as kinematic interaction. For the buildings having multiple basements, effect of both the interaction needs to be considered to obtain the real behavior of the structure. Many researchers ( [1], [2], [3] ) carried out the study on the buildings resting on ground while the effect of dynamic soil structure interaction for buildings with multiple basements are only studied for some hypothetical structures ( [1], [4], [5] ). The behavior of hypothetical structure can be significantly different from that of real-life structures resting on layered soil. Further, when the building is provided with multiple basements, the effect of presence of water level and its variation under seismic condition still requires attention.

A. Why considering soil structure interaction is important for the building with basements?

In the usual situation, tall buildings are mostly accompanied by a deeper basement. The deep basement is constructed with the help of diaphragm wall which serves as a permanent part of the structure to bear the surrounding soil pressure. As shown in figure 1, The diaphragm wall may have a slipping connection or a tied connection. The former allows the sliding between the diaphragm wall and the side wall and it is employed to have a waterproof isolation layer between them. However, the latter provides a complete contact and does not allow any separation between the diaphragm wall and the side wall. In buildings with basements, generally tied connection is preferred [6]. When the tied connection is employed, the seismic effect of diaphragm wall is transmitted to the structure and the inertial effect of the structure is transmitted to the soil resulting in activating dynamic soil structure interaction. Furthermore, when the numbers of basements are placed on layered soil, the situation may arise in which different part of the basement may experience the different shear wave effect. Due to this, it is important to incorporate basements, basement walls, foundation soil and side soil to study the true behavior of the structure by considering dynamic soil structure interaction. Therefore, in present study an attempt is made to study the effect of dynamic soil structure interaction for the real life building with basements having two types of soil. layered

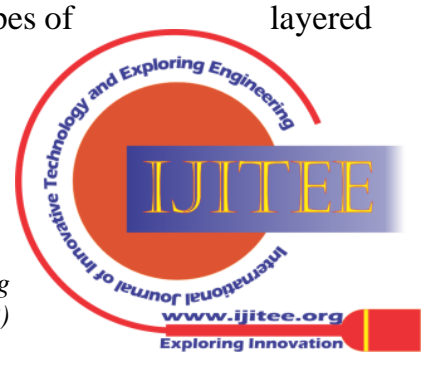




\section{Performance Of Building with Basements Under Seismic Excitation Considering Soil Structure Interaction}

Analysis is performed by Direct method to sought answers to the following questions: - What is the influence zone need to be incorporated in the analysis model?

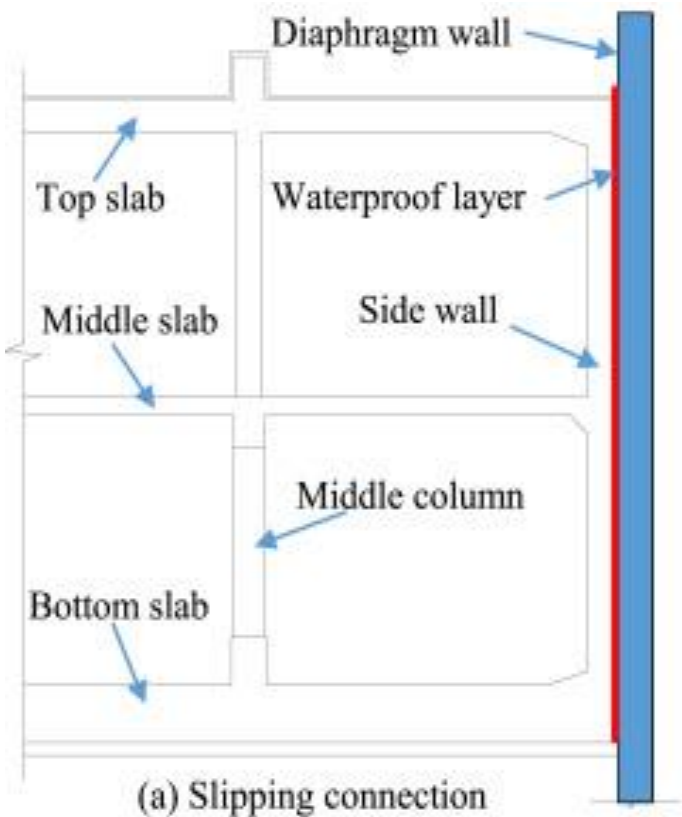

(a) Slipping connection

What is the effect of dynamic soil structure interaction on building with multiple basement?

How does the building with multiple basements behave under different water level condition?

What is the effect of reducing rigidity of basements?

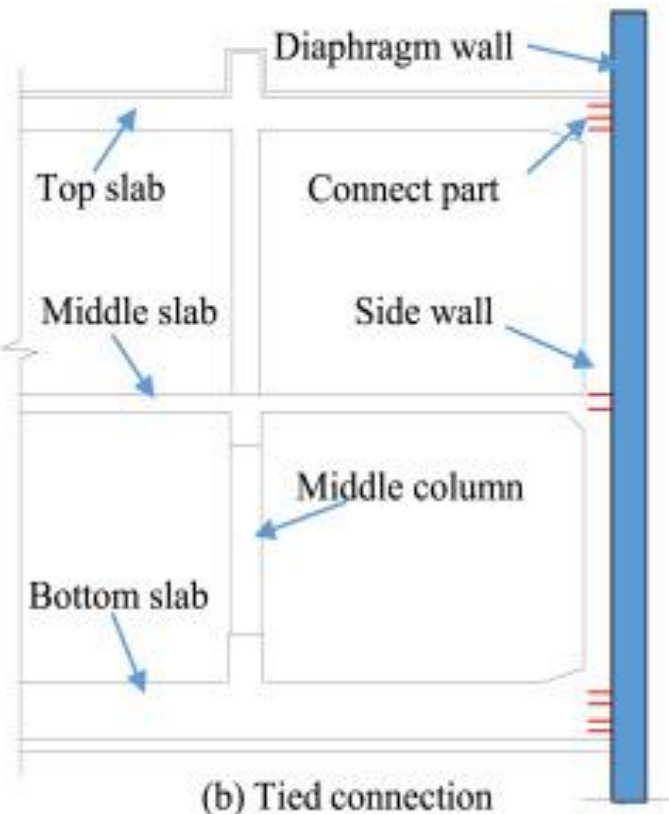

(a)

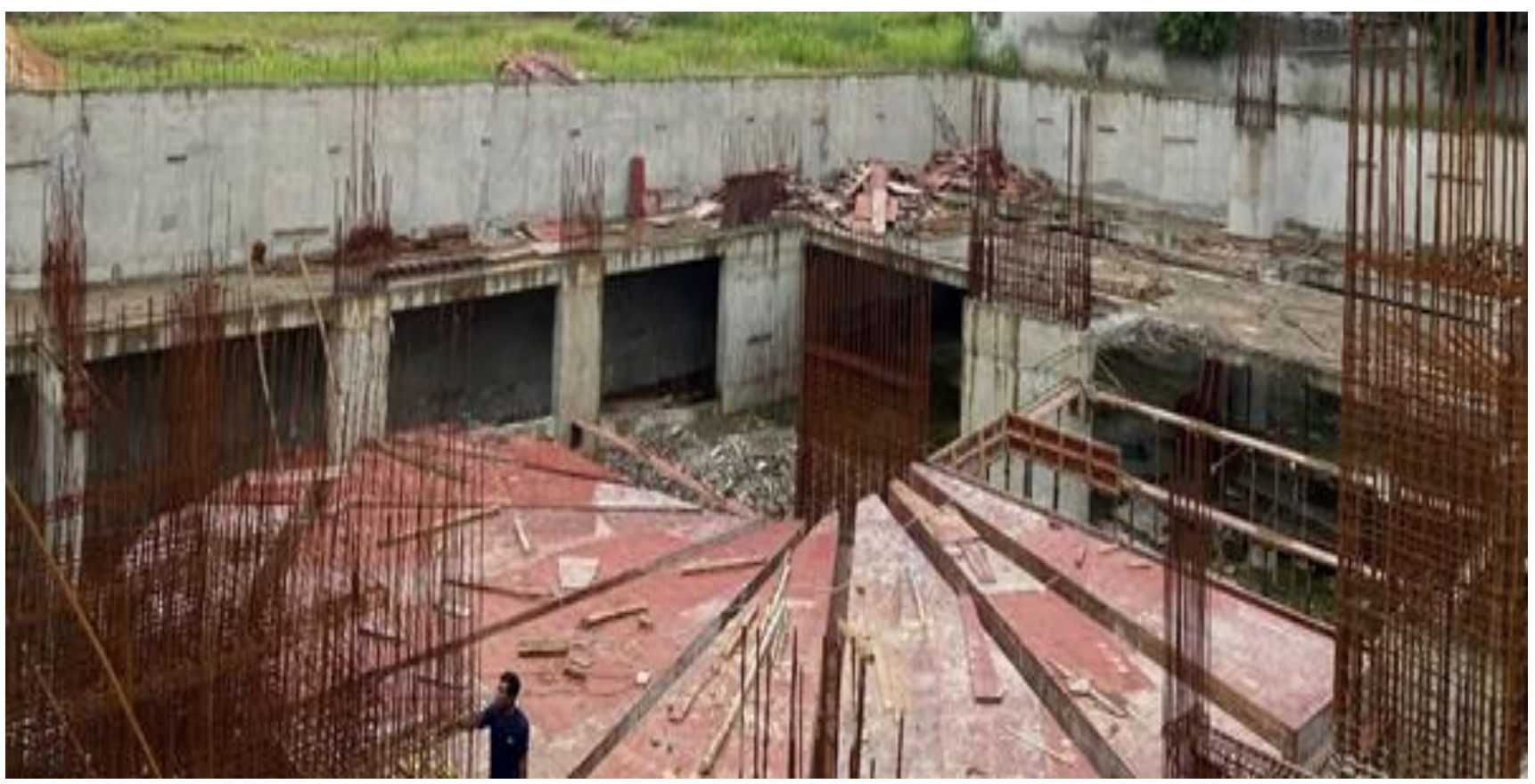

(b)

Picture Courtacy : Obrain from Synergy group

\section{SYSTEM UNDER INVESTIGATION}

This section provides the relevant information like building structural layout, modelling parameters, soil profile and water level conditions considered in the study.

\section{A. Building structural layout and modelling parameters}

Dynamic soil structure interaction is carried out for a building with seventeen storeys above ground and five basements. To consider the effect of rigidity of below grade structure, number of basements is varied from five to three.

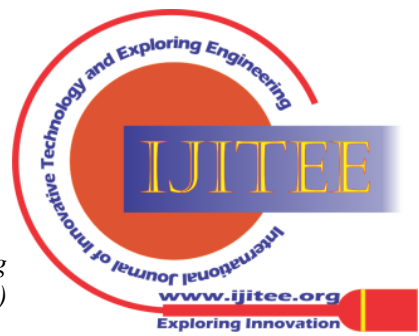




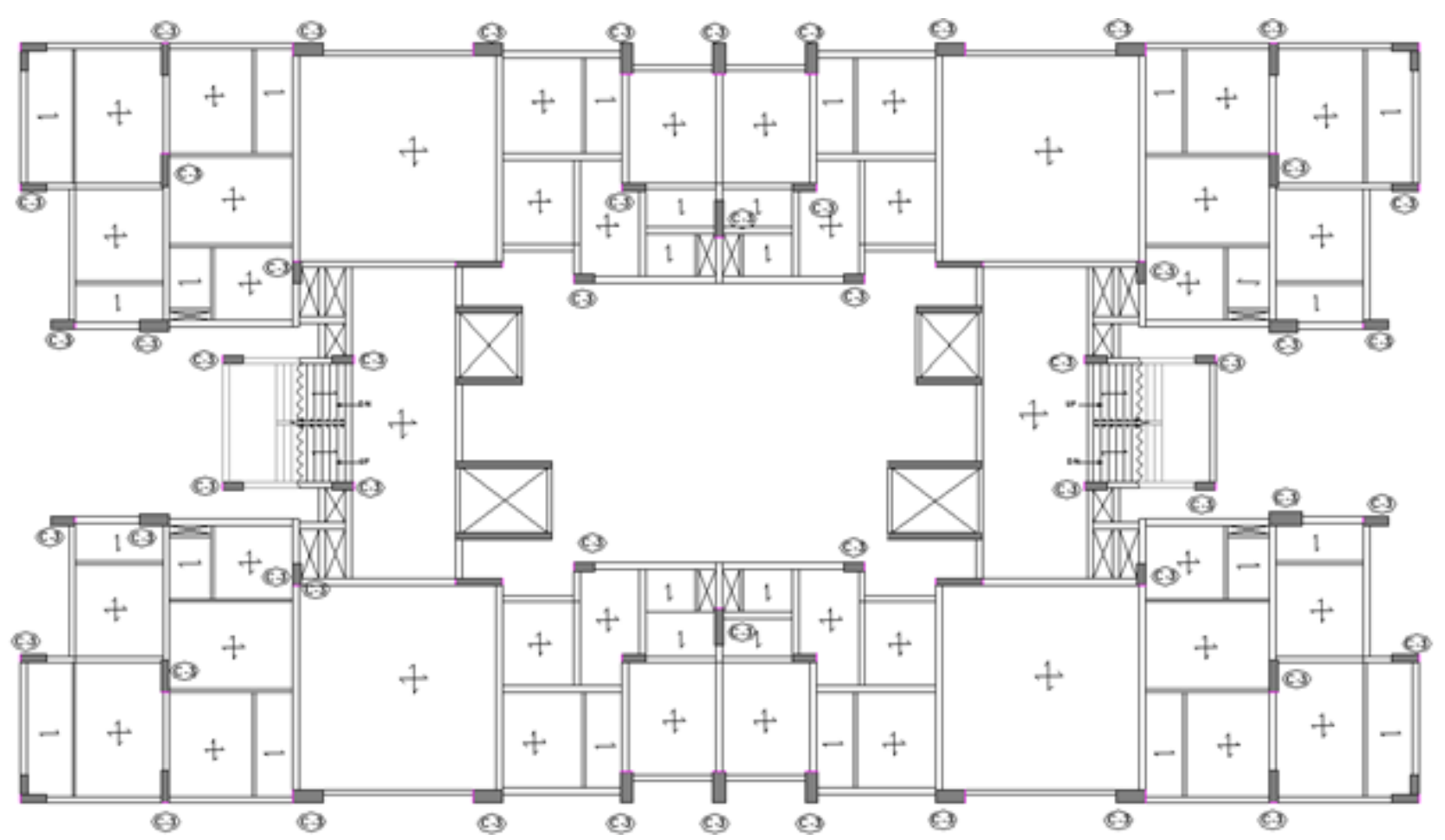

(a)

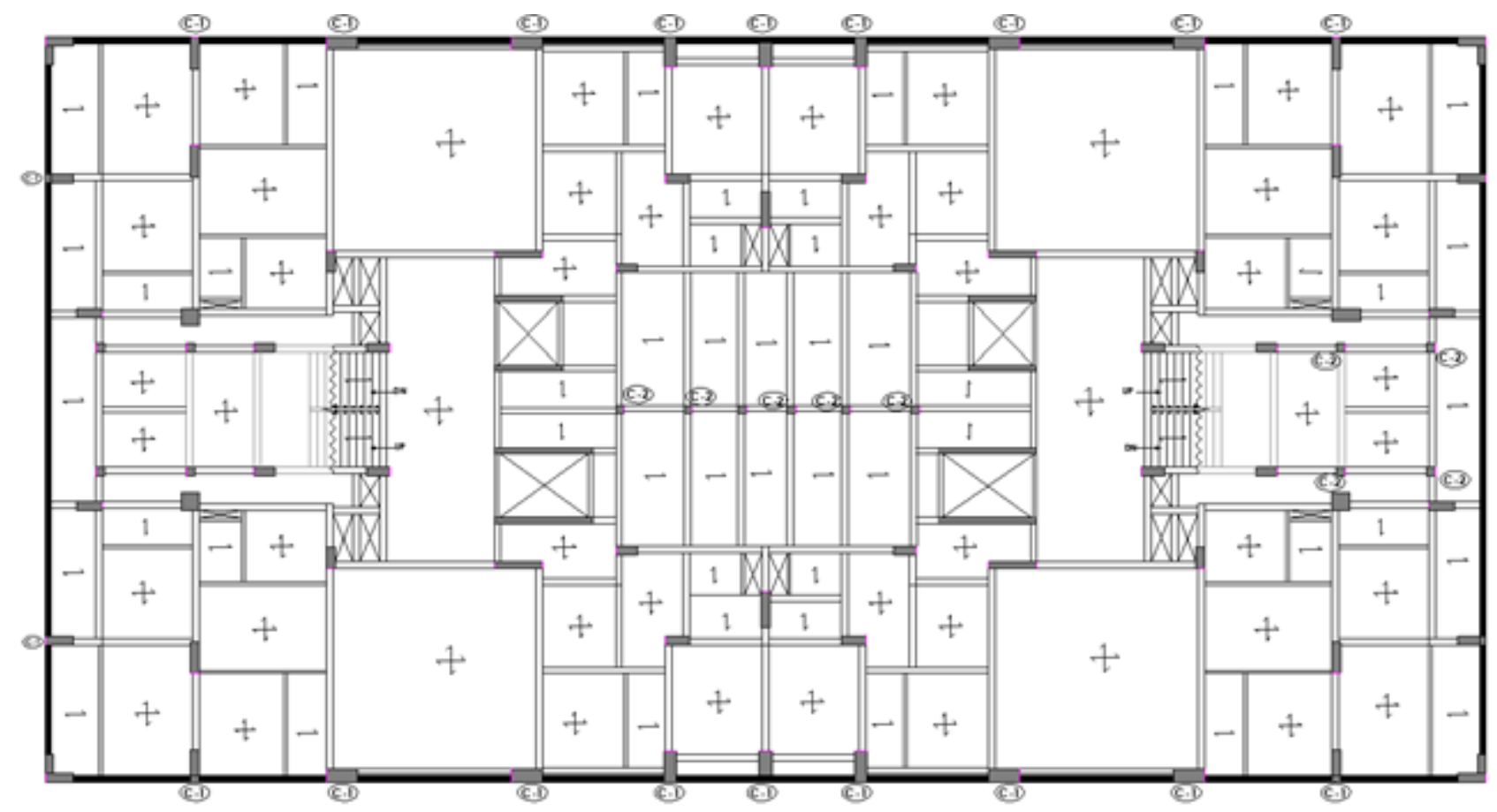

(b)

Figure 2 Structural layout (a) Typical stories (b) Basement stories

Table 1 Grade of materials

\begin{tabular}{|c|c|c|c|c|}
\hline \multicolumn{5}{|c|}{ Characteristic compressive strength of concrete $\left(\mathrm{N} / \mathrm{mm}^{2}\right)$} \\
\hline Columns & Beams & Slabs & Shear walls & Diaphragm walls \\
\hline 30 & 25 & 25 & 30 & 30 \\
\hline \multicolumn{5}{|c|}{ Yield strength of rebar $\left(\mathrm{N} / \mathrm{mm}^{2}\right)$} \\
\hline \multicolumn{5}{|c|}{500} \\
\hline
\end{tabular}

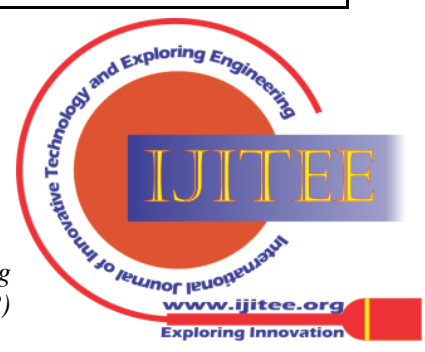


Performance Of Building with Basements Under Seismic Excitation Considering Soil Structure Interaction

Table 2 Section properties

\begin{tabular}{|c|c|c|c|c|c|c|}
\hline \multicolumn{2}{|c|}{ Columns (mm) } & Beams (mm) & Slab (mm) & \multicolumn{2}{|c|}{ Shear wall (mm) } & $\begin{array}{l}\text { Diaphragm wall } \\
\text { thickness (mm) }\end{array}$ \\
\hline $\begin{array}{l}\text { Perimeter column only } \\
\text { for underground stories }\end{array}$ & $600 \times 1200$ & \multirow{3}{*}{$300 \times 600$} & \multirow{3}{*}{150} & Core walls & 200 & \multirow{3}{*}{ 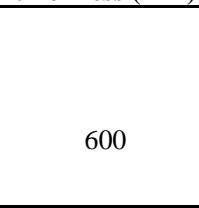 } \\
\hline All square columns & $500 \times 500$ & & & $\begin{array}{l}\text { Other then core } \\
\text { walls }\end{array}$ & 300 & \\
\hline $\begin{array}{l}\text { Column above basement } \\
\text { level }\end{array}$ & $400 \times 1200$ & & & & & \\
\hline \multicolumn{7}{|c|}{$\begin{aligned} \text { Notes: } & \\
\text { 1. } & \text { Slab is modelled for membrane behaviour while shear walls and diaphragm walls are modelled for shell thin behaviour. } \\
\text { 2. } & \text { Stiffness modifiers are applied as per IS 16700:2017 }\end{aligned}$} \\
\hline
\end{tabular}

Table 3 Loading

\begin{tabular}{|c|c|c|c|}
\hline $\begin{array}{l}\text { Floor finish } \\
\left(\mathbf{k N} / \mathbf{m}^{2}\right)\end{array}$ & $\begin{array}{c}\text { Live load on typical } \\
\text { floors } \\
\left(\mathbf{k N} / \mathbf{m}^{2}\right) \\
\end{array}$ & $\begin{array}{l}\text { Live load on basement floors } \\
\qquad\left(\mathrm{kN} / \mathrm{m}^{2}\right)\end{array}$ & $\begin{array}{l}\text { Wall load (on all beams) } \\
\text { (kN/m) }\end{array}$ \\
\hline 1.5 & 2 & 5 & 13.8 \\
\hline
\end{tabular}

\section{B. Soil Profile}

In the present study two types of layered soil is considered namely medium to hard soil and soft to medium soil. The soil properties are shown in the tables below: -

Table 4 Medium to hard soil data

\begin{tabular}{|c|c|c|c|}
\hline $\begin{array}{l}\text { Soil layer in } \\
\text { (m) }\end{array}$ & $\begin{array}{c}\text { Modulus of } \\
\text { elasticity } \\
\left(\mathbf{k N} / \mathbf{m}^{2}\right)\end{array}$ & $\begin{array}{l}\text { Shear modulus } \\
\qquad\left(\mathbf{k N} / \mathbf{m}^{2}\right)\end{array}$ & Poisson ratio \\
\hline 1 & 150076 & 51714 & 0.451 \\
\hline 2 & 271544 & 90351 & 0.439 \\
\hline 3 & 376757 & 132103 & 0.426 \\
\hline 4 & 501459 & 177696 & 0.411 \\
\hline 5 & 633908 & 226557 & 0.399 \\
\hline 6 & 754597 & 271048 & 0.392 \\
\hline 7 & 820823 & 294836 & 0.392 \\
\hline 8 & 1068433 & 384605 & 0.389 \\
\hline 9 & 1276578 & 461859 & 0.382 \\
\hline 10 & 1430321 & 514504 & 0.390 \\
\hline 11 & 1655404 & 599784 & 0.380 \\
\hline 12 & 1785888 & 648942 & 0.376 \\
\hline 13 & 1833791 & 664417 & 0.38 \\
\hline 14 & 2014123 & 734010 & 0.372 \\
\hline 15 & 2154948 & 787052 & 0.368 \\
\hline 16 & 2322797 & 851465 & 0.364 \\
\hline 17 & 2910335 & 1071552 & 0.358 \\
\hline 18 & 3274850 & 1225617 & 0.336 \\
\hline 19 & 2986357 & 1096313 & 0.362 \\
\hline 20 & 3087884 & 1137761 & 0.357 \\
\hline 21 & 3108620 & 1142875 & 0.360 \\
\hline
\end{tabular}

\begin{tabular}{|c|c|c|c|}
\hline 22 & 3214143 & 1185156 & 0.356 \\
\hline 23 & 3308824 & 1221870 & 0.354 \\
\hline 24 & 3434751 & 1273073 & 0.349 \\
\hline 25 & 3446833 & 1275660 & 0.351 \\
\hline 26 & 3541004 & 1309543 & 0.352 \\
\hline 27 & 3592445 & 1328597 & 0.352 \\
\hline 28 & 3626721 & 1341243 & 0.352 \\
\hline 29 & 3651560 & 1349431 & 0.353 \\
\hline 30 & 3765135 & 1395541 & 0.349 \\
\hline
\end{tabular}

Table 5 Soft to Medium soil data

\begin{tabular}{|c|c|c|c|}
\hline $\begin{array}{l}\text { Soil layer in } \\
\text { (m) }\end{array}$ & $\begin{array}{c}\text { Modulus of } \\
\text { elasticity } \\
\left(\mathbf{k N} / \mathbf{m}^{2}\right)\end{array}$ & $\begin{array}{c}\text { Shear } \\
\text { modulus } \\
\left(\mathrm{kN} / \mathbf{m}^{2}\right)\end{array}$ & Poisson ratio \\
\hline $0-3$ & 32500 & 13000 & 0.25 \\
\hline $3-15$ & 50000 & 20000 & 0.25 \\
\hline $15-20$ & 75600 & 28000 & 0.35 \\
\hline $20-30$ & 255650 & 98500 & 0.45 \\
\hline $30-45$ & 574200 & 197000 & 0.45 \\
\hline $45-60$ & 1393450 & 480500 & 0.45 \\
\hline $60-75$ & 2021300 & 697000 & 0.45 \\
\hline $75-90$ & 2604200 & 898000 & 0.45 \\
\hline 90-105 & 8439000 & 2910000 & 0.45 \\
\hline $105-115$ & 8772500 & 3025000 & 0.45 \\
\hline
\end{tabular}

Blue Eyes Intelligence Engineering and Sciences Publication (BEIESP) 10 Copyright: All rights reserved.

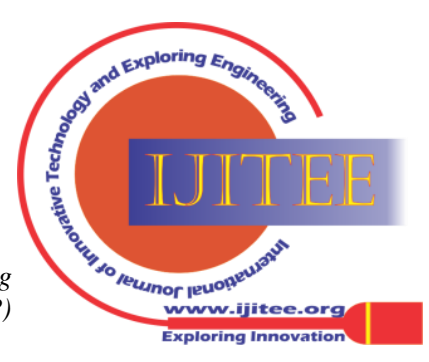


In the present study, unit weight of soil is considered as 17.55 $\mathrm{kN} / \mathrm{m}^{3}$ for both the soil types.

\section{Water level conditions}

To determine the drag and buoyancy effect of water pressure, different water level conditions namely no water in the vicinity, water level at ground level, water level below basement and water level with gradient are studied.

\section{Mathematical modelling for dynamic soil structure interaction}

In the present study, modelling for soil behavior is carried out by Direct method, using eight node solid element in the general-purpose finite element software SAP 2000. A schematic view of mathematical model is shown in figure 3

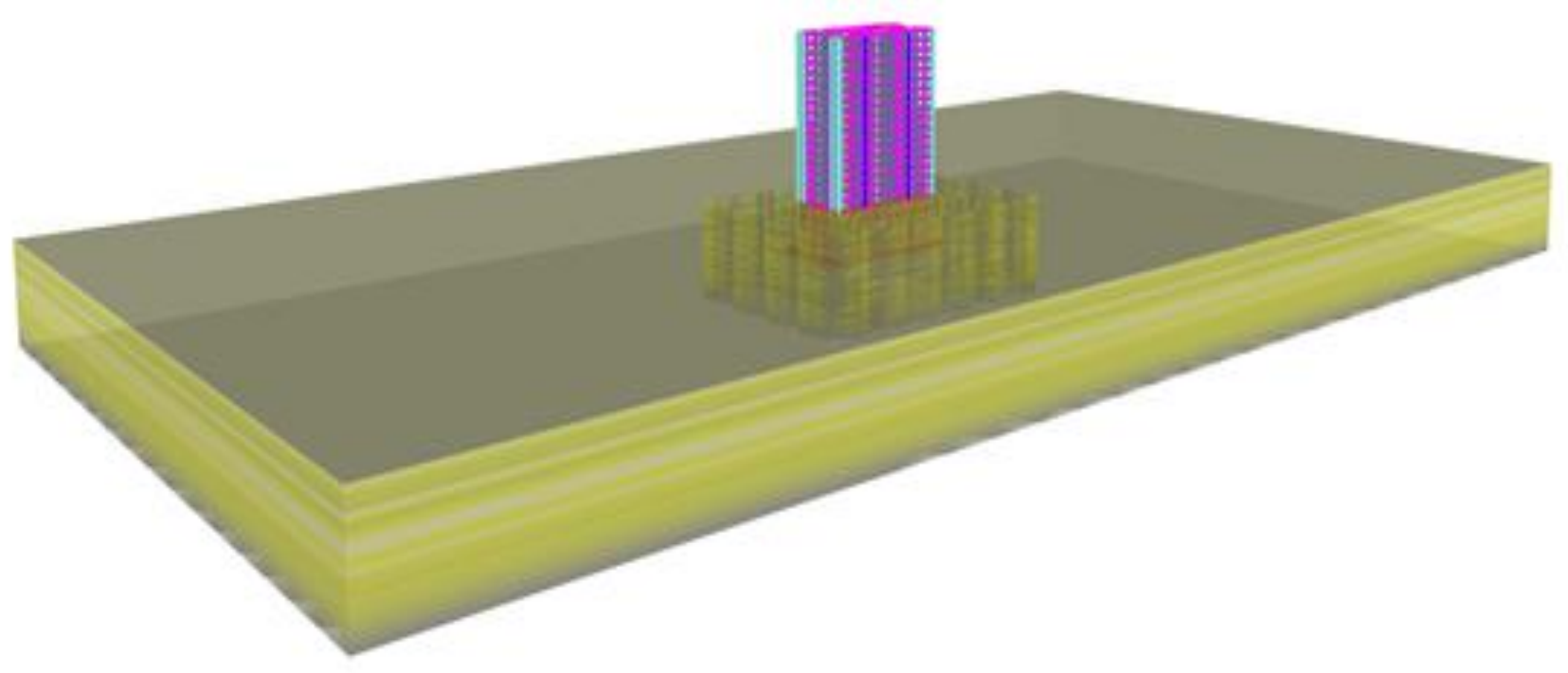

Figure 3 Mathematical modelling by Direct method for Dynamic Soil Structure Interaction

In order to obtain accuracy, the solid elements are required to mesh. The maximum mesh size of $\frac{\lambda}{4}$ to $\frac{\lambda}{10}$ can be provided as given by [7] :

Where,

$\lambda=V s \times T s$

Where,

$V s=$ Shear wave velocity of soil

$T s$ = time period of the exciting frequency of the soil medium as $\frac{4 H}{V s}$,

Where, $\mathrm{H}=$ Height of soil medium

When the dynamic soil structure interaction is performed it is necessary that entire soil mass should move together. However, when there is mesh discontinuity the mass does not move together. In order to account for the effect caused by mesh discontinuity, SAP 2000 requires edge constraints to be provided wherever there is mesh discontinuity.

In the direct method, the infinite soil medium in obtain artificial boundary for modelling purpose generally known as unbounded soil medium [8]. However, as the truncation of soil medium may result into reflection of propagation waves back into the medium, it is necessary to provide special boundary elements which are called as absorbing/transmitting boundaries [8].

In SAP 2000, this can be done by Maxwell's exponential link element. The properties of link element are calculated from the research work done by [9]. The damping coefficient is given by [9]

$$
C d=\rho \times V s
$$

Where,

$C d=$ Damping coefficient

$\rho=$ Mass density of soil mathematical model is truncated after some distance to

$V s=$ Shear wave velocity of soil

\section{ANALYSIS}

\section{A. Assumptions}
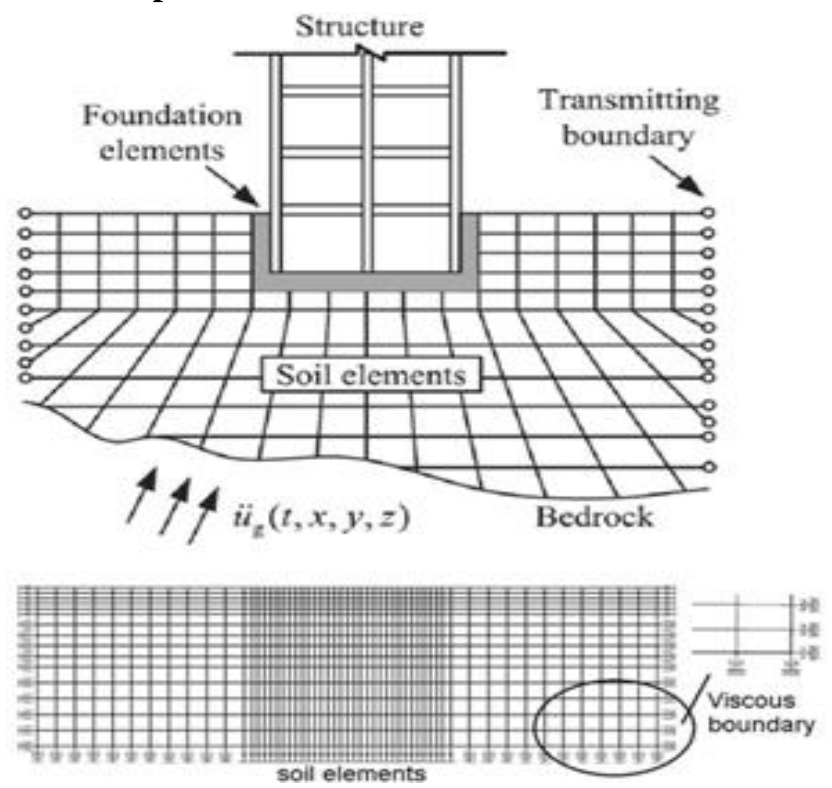

The following assumptions are made for performing analysis:

- The Diaphragm wall and main building structure is provided with tied connection rather than slipping connection so that the diaphragm wall and main building structure behave as one unit.

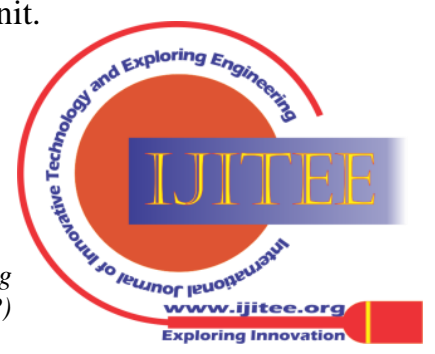


- It is assumed that both the material soil and structure time and storage for general building structures.

- It is assumed that the effect of adjacent structures on the main building structure is negligible. As in the case of tall building surrounded by low to mid-rise structures.

- $\quad$ This assumption is justified from the research carried out by [10]

- The perfect bond between soil and structue is assumed, as it will be the worst case ( [11])

\section{B. Analysis}

In the present study, nonlinear time history analysis is performed under major component of Bhuj earthquake (figure 5) applied in two orthogonal directions. The time history of Bhuj earthquake (figure 5) is in $\mathrm{cm} / \mathrm{s}^{2}$ unit and therefore the scale factor $1 / 100$ is applied to convert it into $\mathrm{m} / \mathrm{s}^{2}$ unit. Rayleigh damping is used to model the damping behavior by using 5\% damping ratio.

The sensitivity analysis is performed for $1 B, 2 B, 3 B, 4 B, 5 B$ soil model to determine the influence zone,

where $\mathrm{B}$ is the width of building in the direction considered

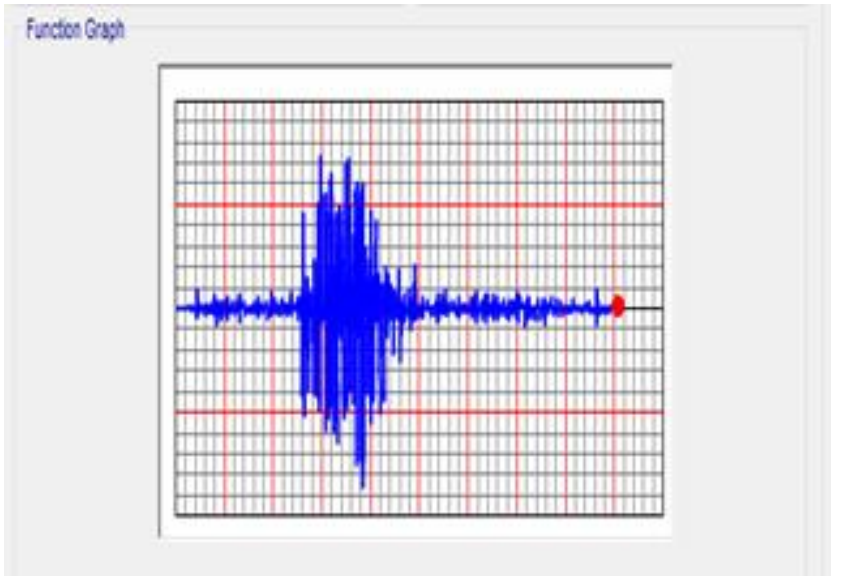

Figure 5 Time history function of $180^{\circ}$ component of Bhuj Earthquake

\section{RESULTS AND DISCUSSION}

This section discusses the result of the present study. Specifically, influence zone to be considered for modelling soil, effect of dynamic soil structure interaction on building with multiple basements, effect of pore water pressure, effect of reducing number of basements.

\section{A. Influence zone to be considered for modelling soil}

When considering soil structure interaction for earthquake case, the structure resting on the soil can be visualized similar to a ship floating in the sea i.e. structure resting on an elastic half space. Under the event of an earthquake, waves dissipate in all the direction and soil mass tends to vibrate at its own fundamental frequency which is known as the free field frequency/time period of the site ( [12])

The maximum displacements of soil mass obtained under the earthquake is known as free field displacement. The free field displacement is extremely important for deciding the influencing zone for dynamic soil structure interaction. When elaborate finite element modelling of soil is done, the soil boundary should be taken sufficient distance away from the structure to prevent reflection of waves back into the behave in linear elastic manner as this assumption saves

unbounded medium. So, the question arises is what is the sufficient distance where the soil boundary can be truncated to prevent wave reflection and how to decide it?

Here comes the role of free field displacement. When structure is modelled together with the soil, displacement of soil tends to deviate from the free field displacement which is termed as absolute displacement. As our focus is on one particular building and even it is assumed that the surrounding structures are such that they do not affect the main structure, the absolute displacement of soil must approach to the free field displacement after certain finite distance [13]. Thus, the distance at which the absolute displacement and free field displacement matches is considered in the modelling of dynamic soil structure interaction.

In order to decide the influencing length and width, sensitivity analysis is performed for $1 B, 2 B, 3 B, 4 B, 5 B$ soil model to determine the influence zone,

where B is the width of building in the direction considered. With the help of free field displacement and absolute displacement, the length and width of the influence zone can be decided while the depth cannot be decided by the free field displacement. Therefore, Time period of soil-structure system is used as a parameter to determine the depth of soil to be model.

In order to decide the influencing depth, sensitivity analysis is performed by increasing the depth of soil until the time period of soil-structure system attains a constant value.

Table 5 Influence Length and Width.

\begin{tabular}{|c|c|c|c|l|}
\hline $\begin{array}{c}\text { Type of } \\
\text { soil }\end{array}$ & $\begin{array}{c}\text { Free field } \\
\text { displacement } \\
(\mathrm{mm})\end{array}$ & $\begin{array}{c}\text { Absolute } \\
\text { displacement } \\
(\mathrm{mm})\end{array}$ & $\begin{array}{c}\text { Influence } \\
\text { length }\end{array}$ & $\begin{array}{l}\text { Influence } \\
\text { width }\end{array}$ \\
\hline $\begin{array}{c}\text { Medium } \\
\text { to hard }\end{array}$ & 3.06 & 3.23 & $5 \mathrm{~L}^{*}$ & $5 \mathrm{~B} *$ \\
\hline $\begin{array}{c}\text { Soft to } \\
\text { medium }\end{array}$ & 7.74 & 7.91 & $5 \mathrm{~L}^{*}$ & $5 \mathrm{~B} *$ \\
\hline \multicolumn{4}{|c|}{$* \mathrm{~B}$ is the width of building in the direction considered } \\
\hline
\end{tabular}

It is observed from the Table 5 that influence length and width to be considered for modelling soil structure interaction for real life structure comes out to be five times the width of building in the direction considered. Further, the time period gets constant at $30 \mathrm{~m}$ depth for medium to hard soil where the modulus of elasticity of soil is $3766514 \mathrm{KN} / \mathrm{m}^{2}$ and shear wave velocity is $857 \mathrm{~m} / \mathrm{s}^{2}$ while for soft to medium soil time period attains a constant value at $115 \mathrm{~m}$ where the modulus of elasticity is $8772500 \mathrm{KN} / \mathrm{m}^{2}$ and shear wave velocity is $1350 \mathrm{~m} / \mathrm{s}^{2}$. Thus, when the soil is soft more influencing depth need to be considered. As a general recommendation trial depth of soil can be taken where the shear wave velocity is around $1000 \mathrm{~m} / \mathrm{s}^{2}$.

Thus based on the above result influence zone considered for present study is

$5 \mathrm{~B} * 5 \mathrm{~L} * 30 \mathrm{~m}$ for medium to hard soil

Where $\mathrm{B}$ and $\mathrm{L}$ is the width and length of building respectively.

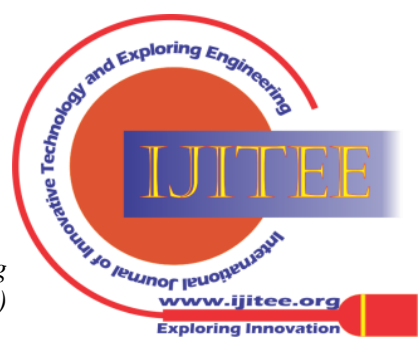




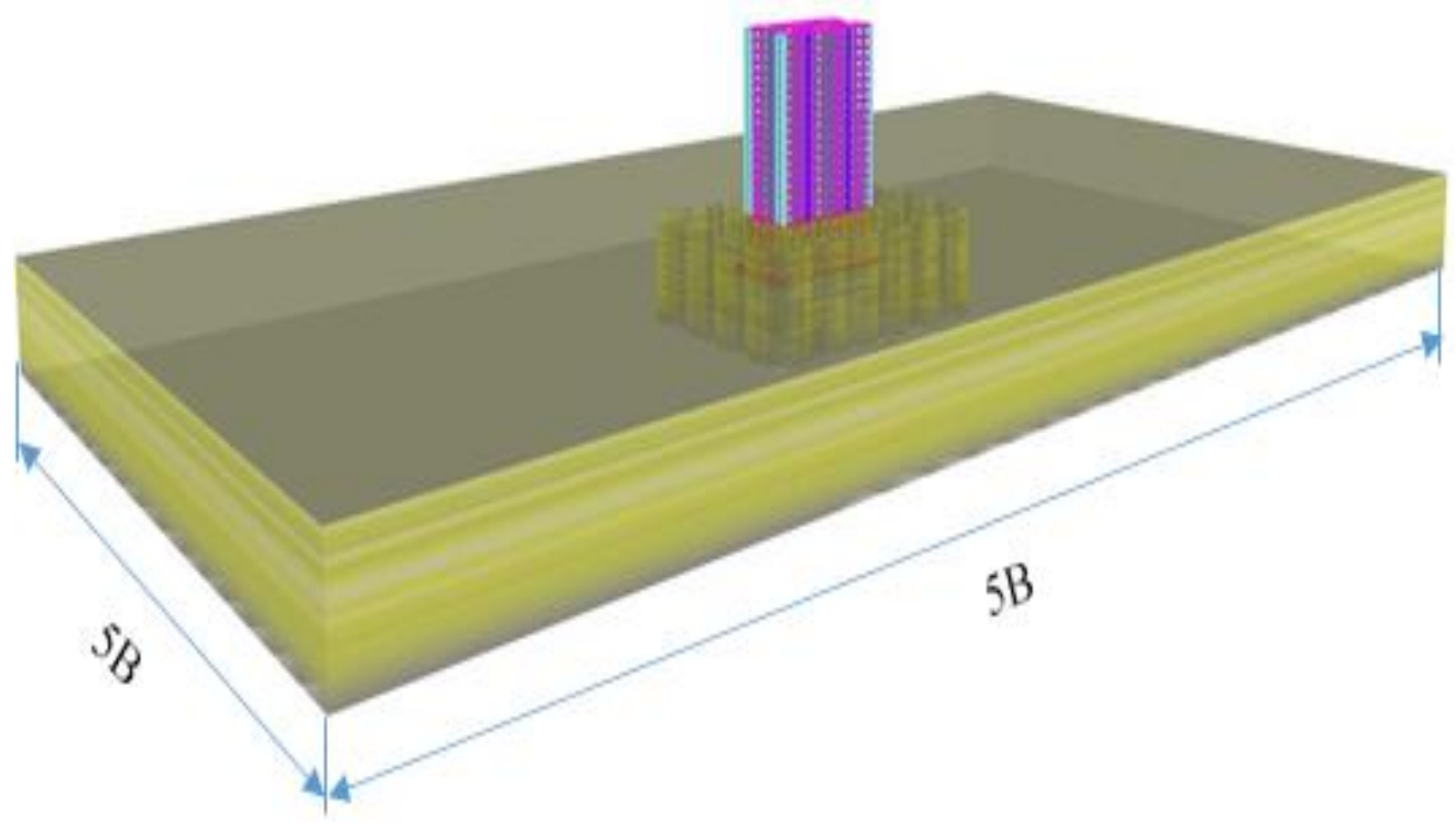

Figure 6 Influence zone for medium to hard soil

$5 B * 5 \mathrm{~L} * 115 \mathrm{~m}$ for soft to medium soil.

Where $\mathrm{B}$ and $\mathrm{L}$ is the width and length of building respectively.

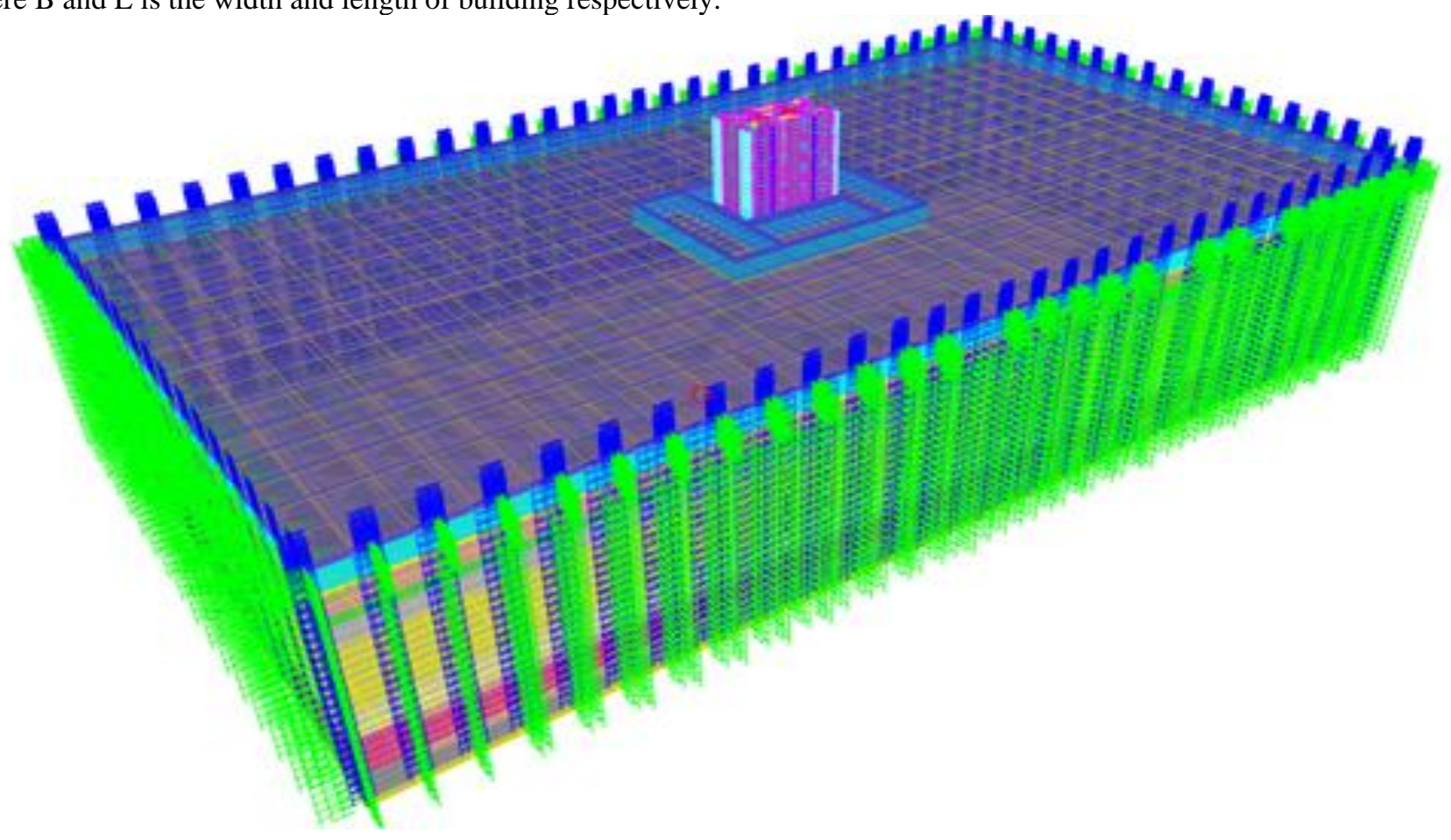

Figure 7 Influence zone for soft to medium soil

Effect of dynamic soil structure interaction on building with five basements:-

Comparison of fixed base structure with the dynamic soil structure interaction: -

According to the results, discussion is divided into two parts namely Comparison of fixed base structure with the dynamic soil structure interaction, Effect of pore water pressure.

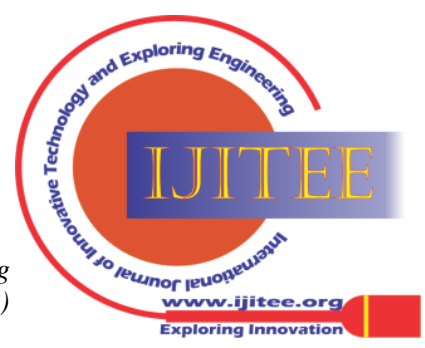




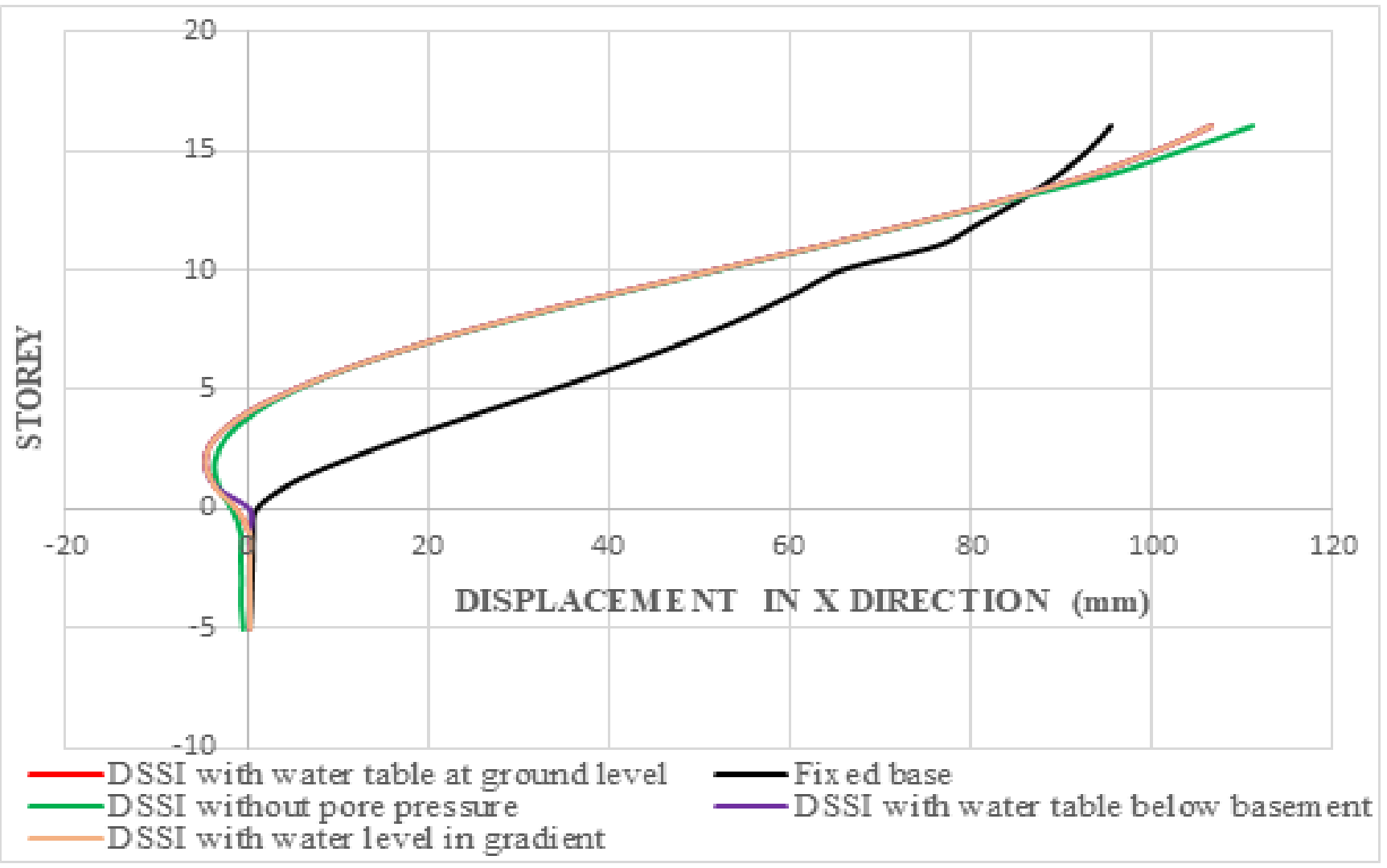

(a)

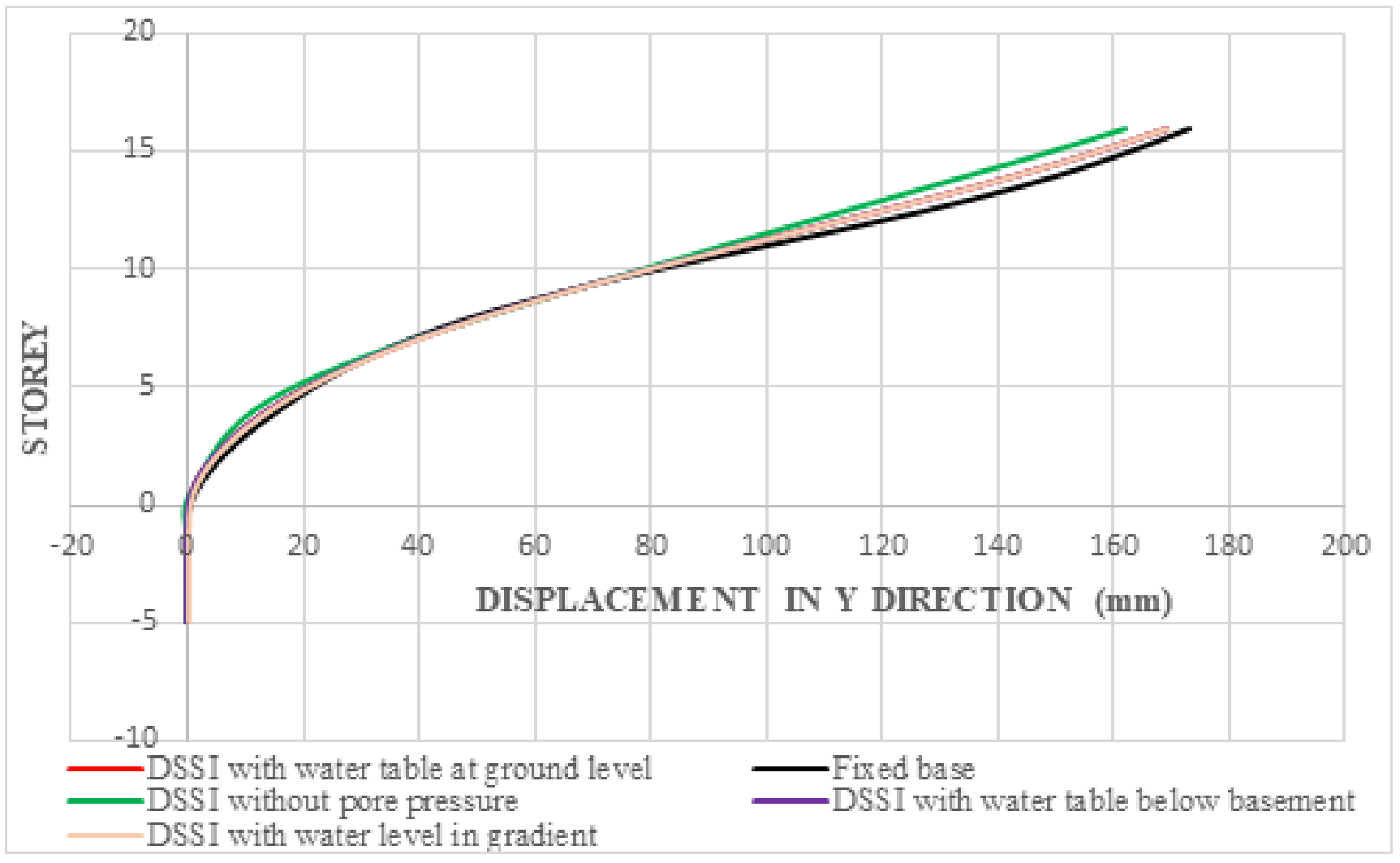

(b)

Figure 8 Displacement of structure for medium to hard soil (a) X direction (b) Y direction

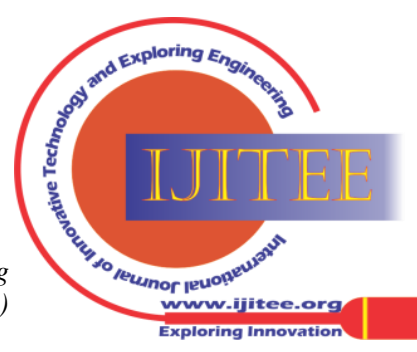




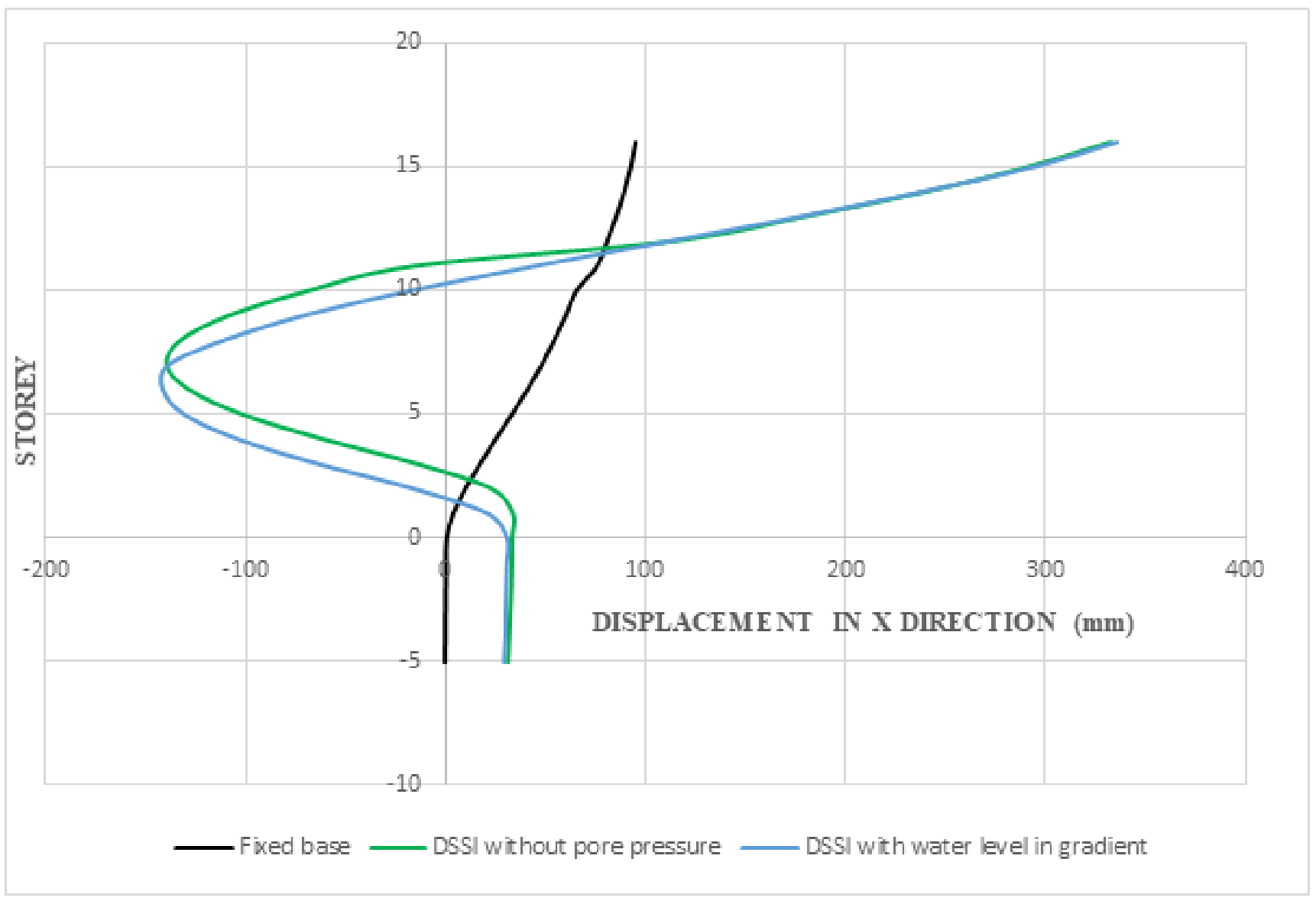

(a)

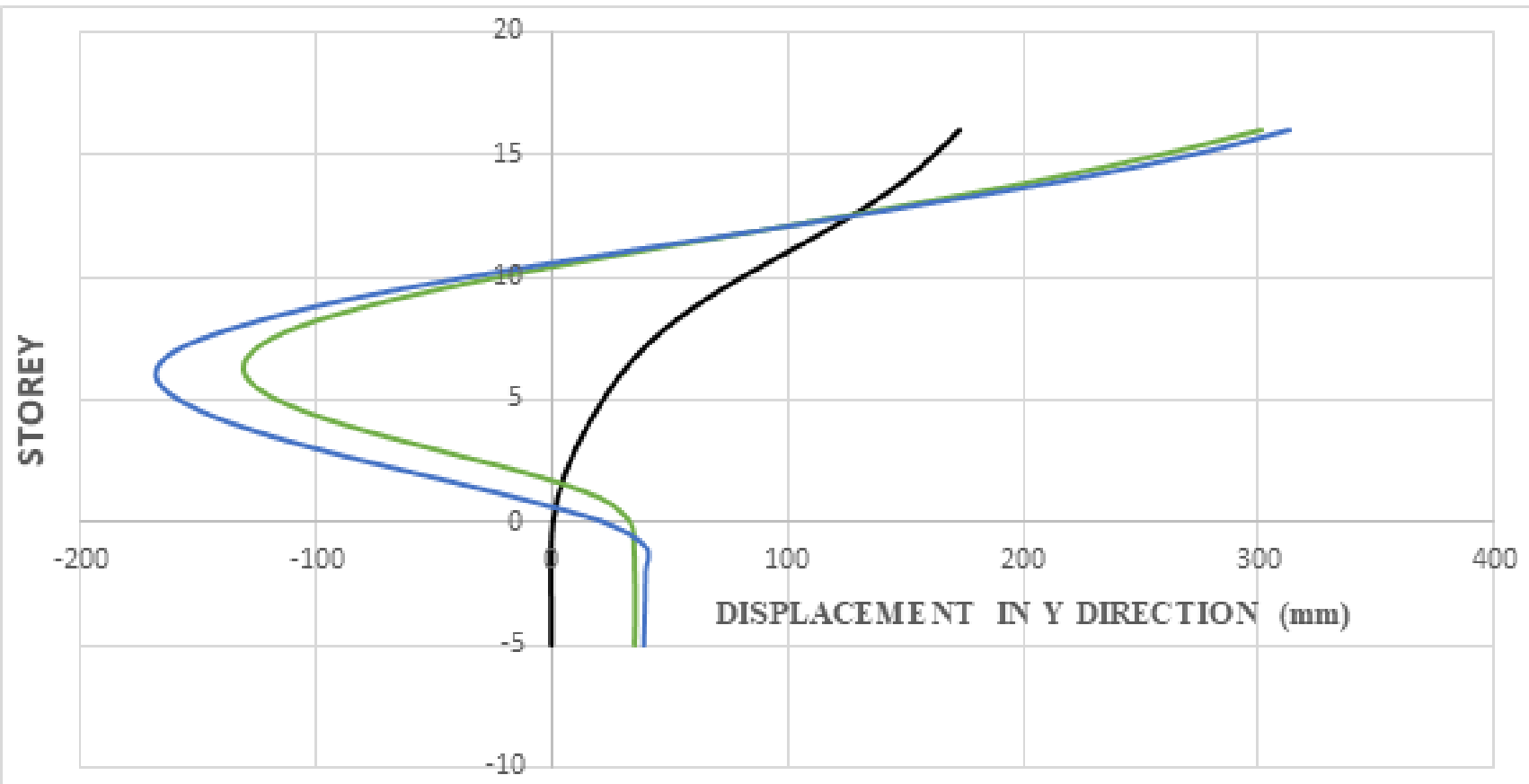

-Fix ed base —DSSI without pore pressure -DSSI with water level in gradient

(b)

Figure 9 Displacement of structure for soft to medium soil (a) X direction (b) Y direction

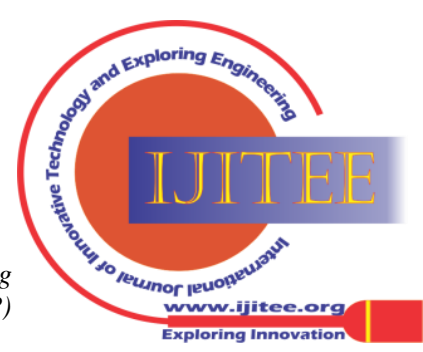




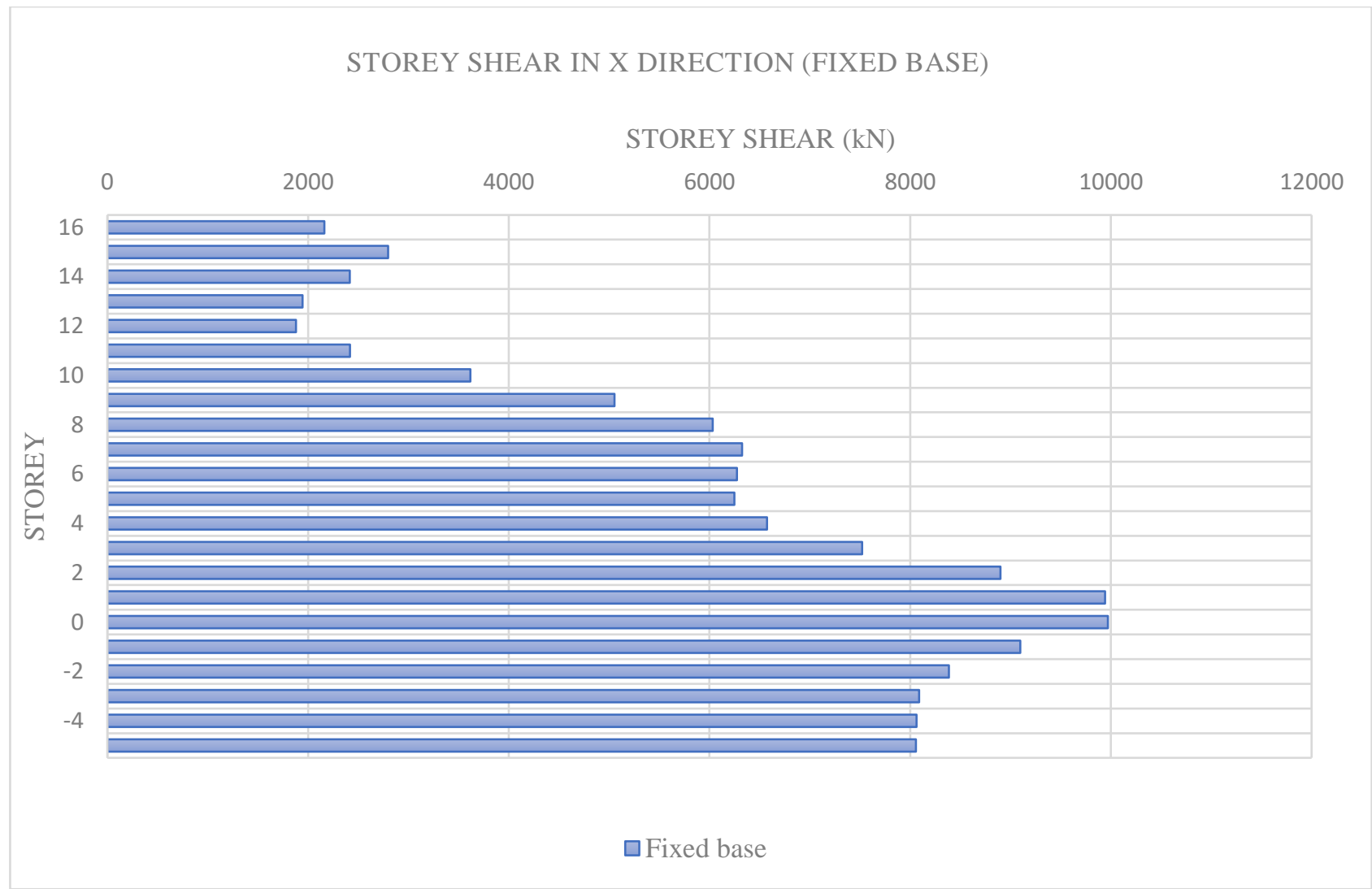

(a)

STOREY SHEAR IN Y DIRECTION (FIXED BASE)

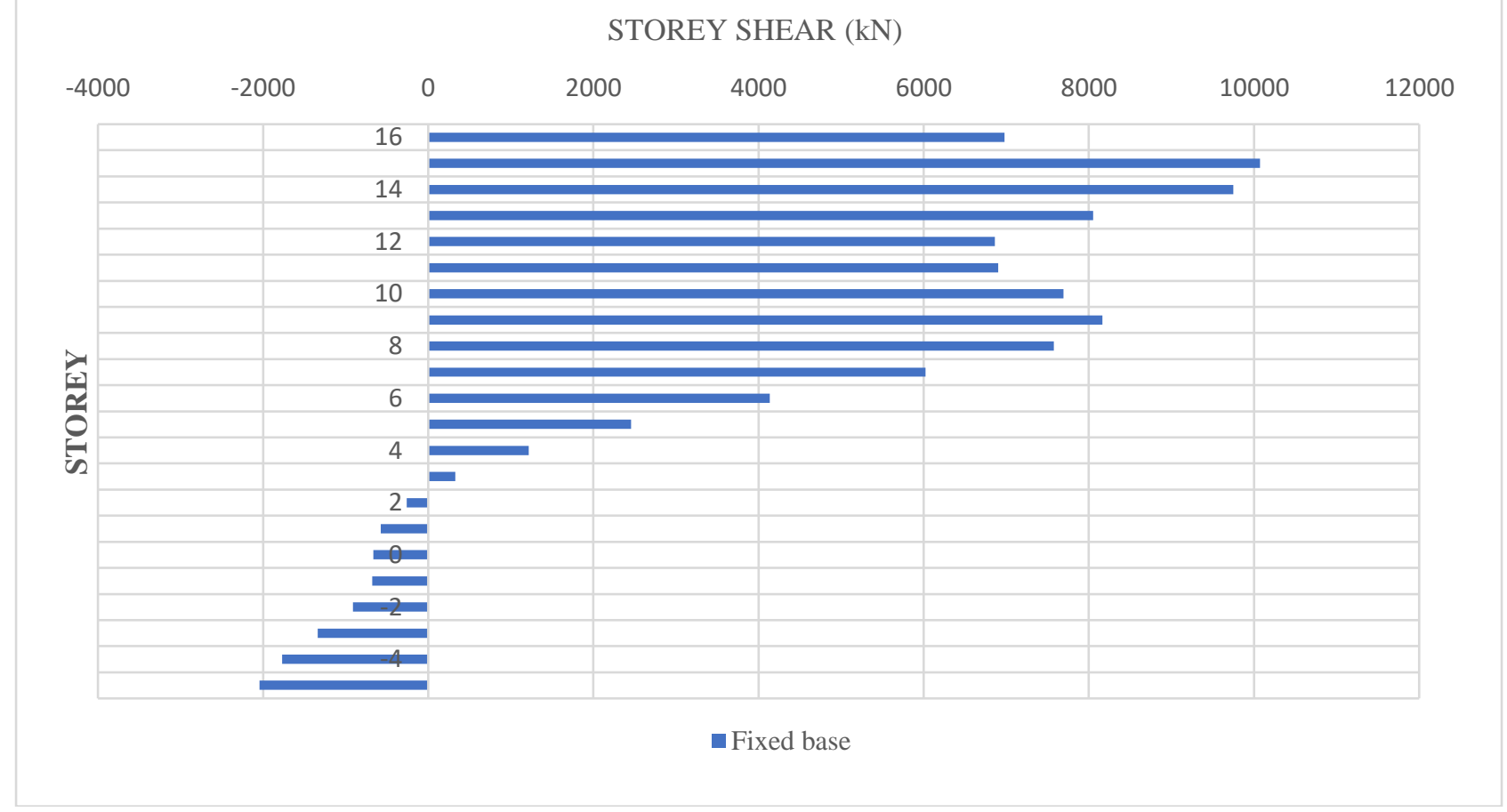

(b)

Figure 10 Storey shear for fixed base condition (a) X direction (b) Y direction

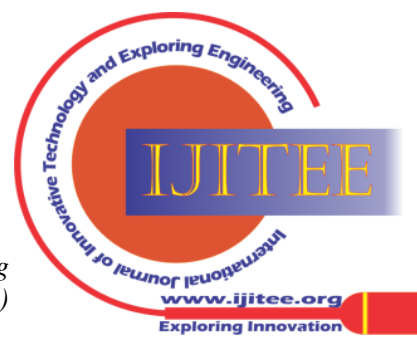




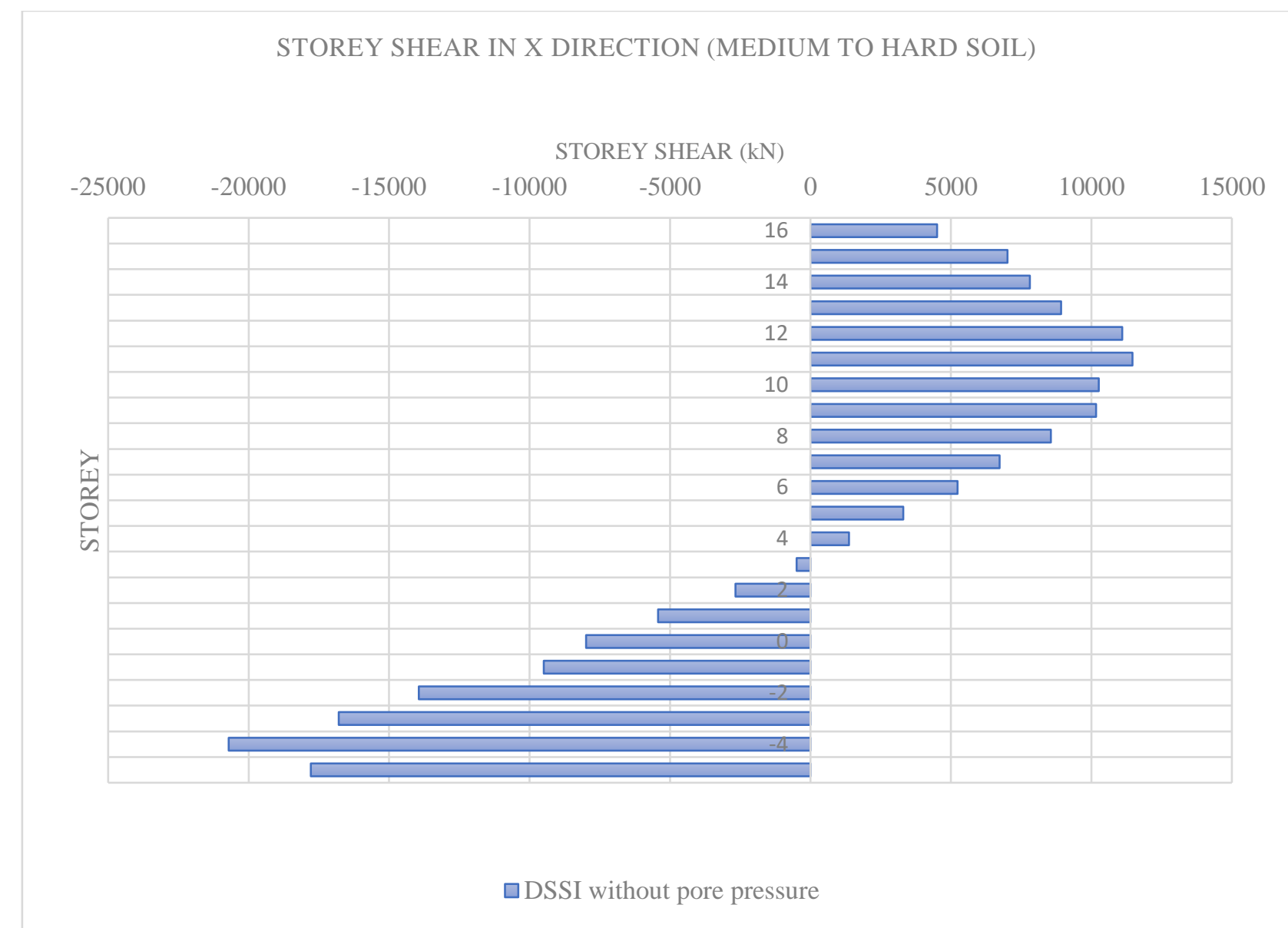

(a)

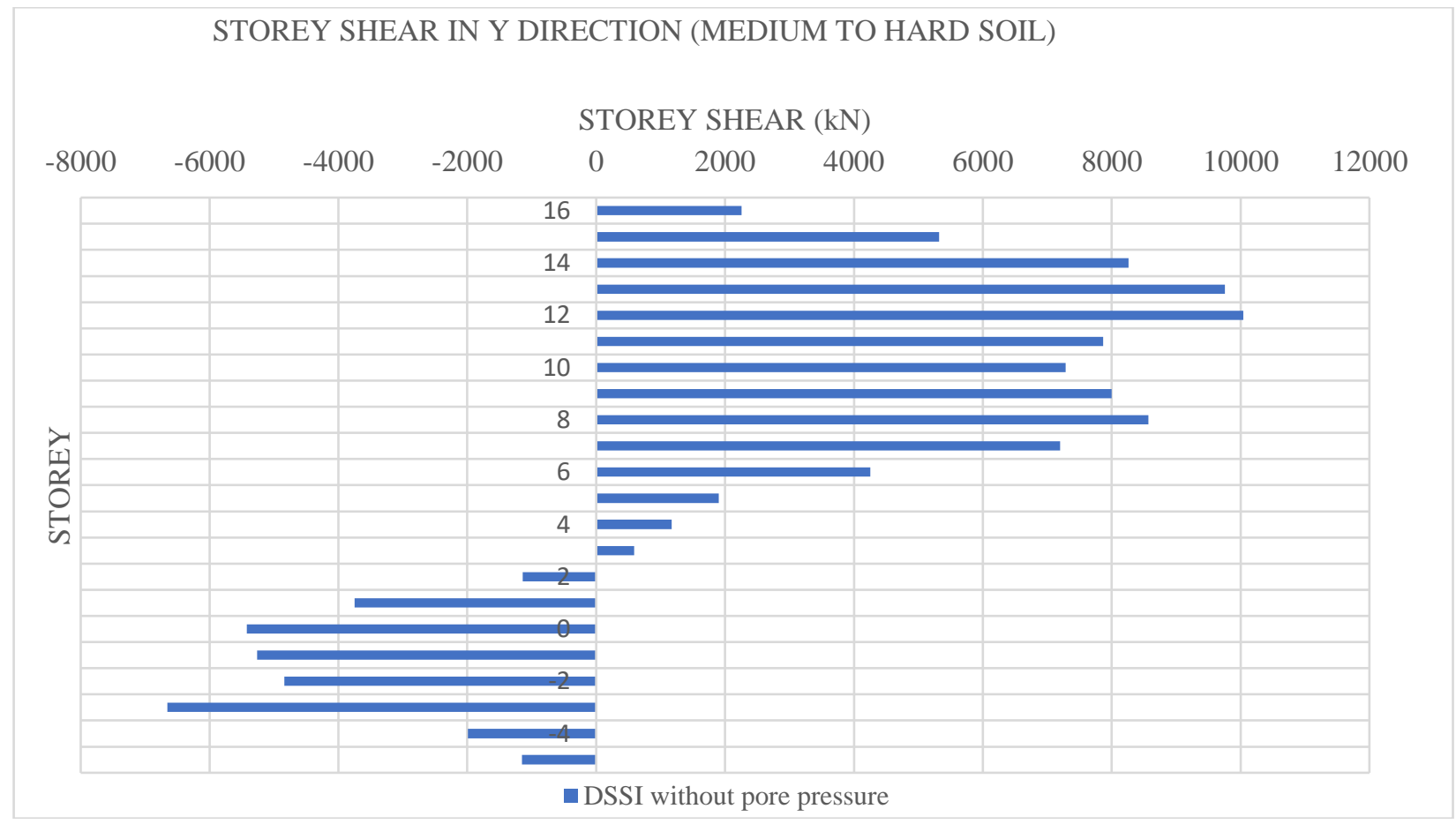

(b)

Figure 11 Storey shear DSSI without pore pressure (a) X direction (b) Y direction (Medium to hard soil)

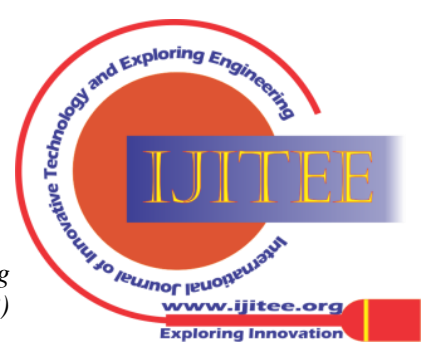


Performance Of Building with Basements Under Seismic Excitation Considering Soil Structure Interaction

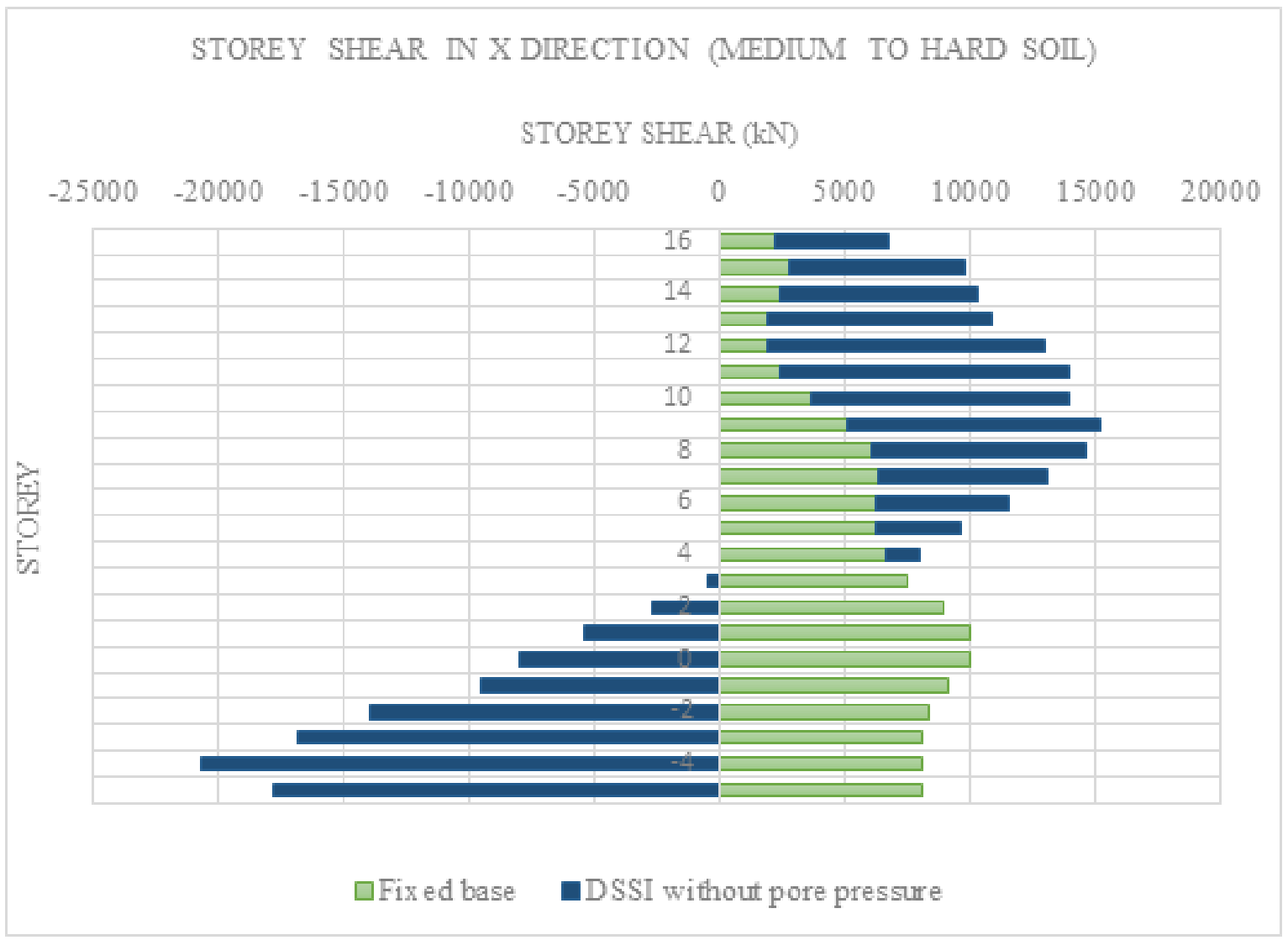

(a)

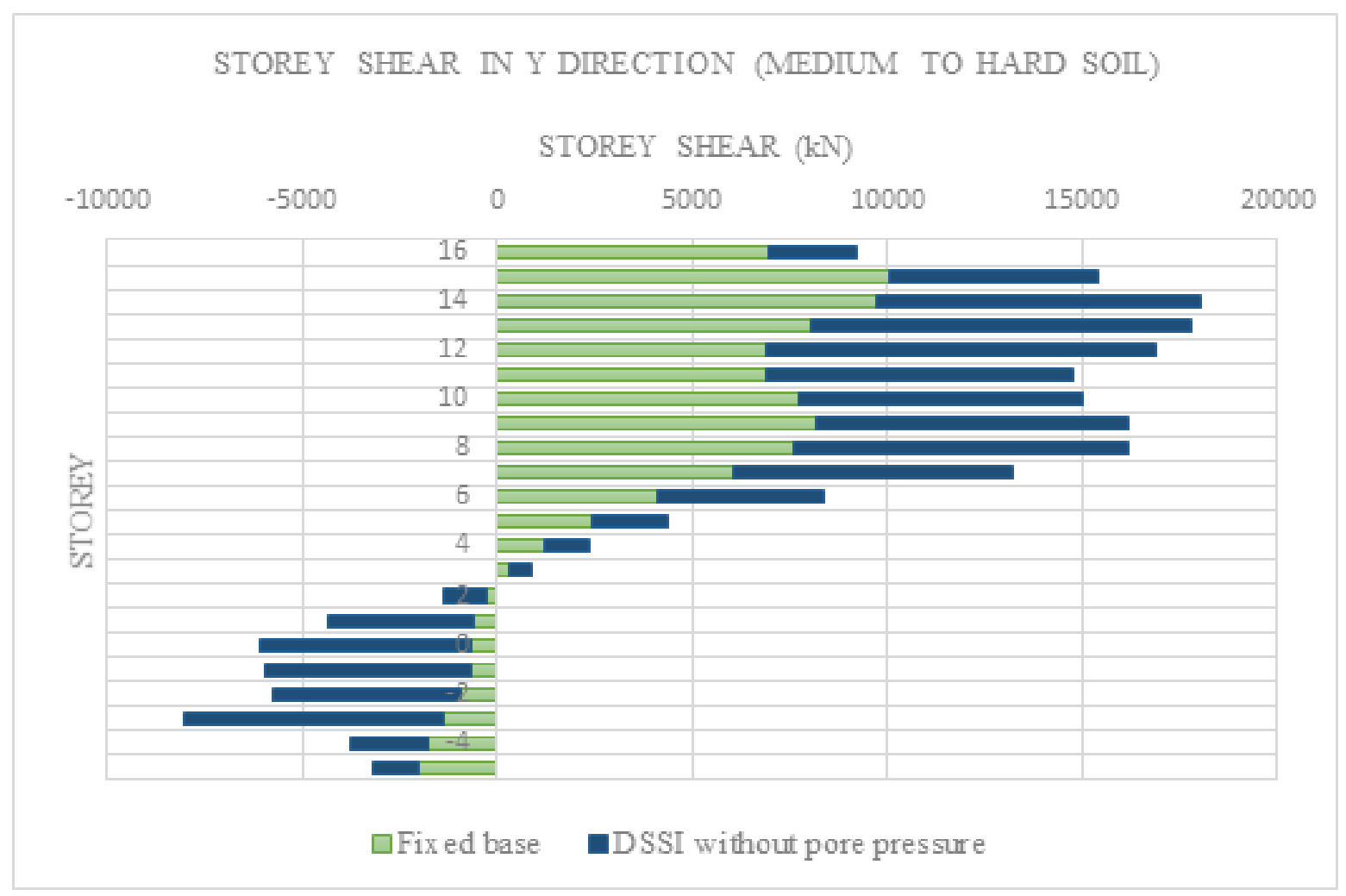

(b)

Figure 12 Comparison of Storey shear for fixed base condition with DSSI without pore pressure (a) X direction (b) Y direction (Medium to hard soil)

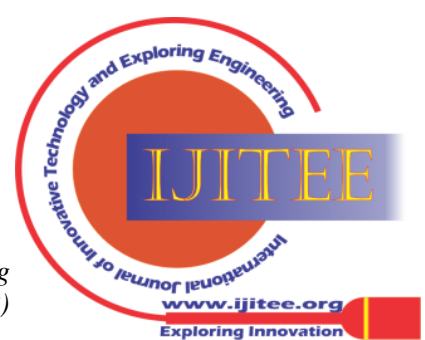




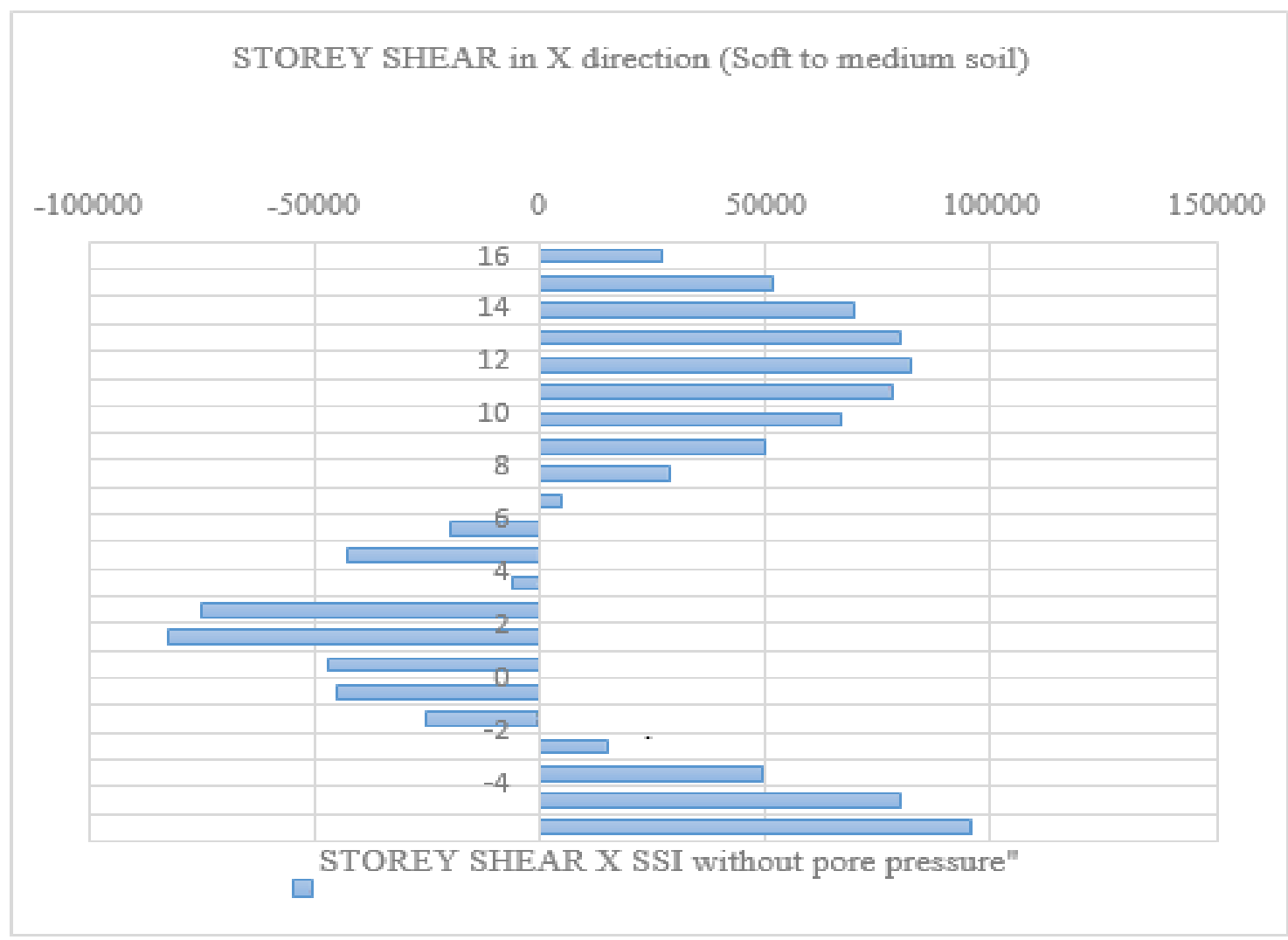

(a) STOREY SHEAR (kN)

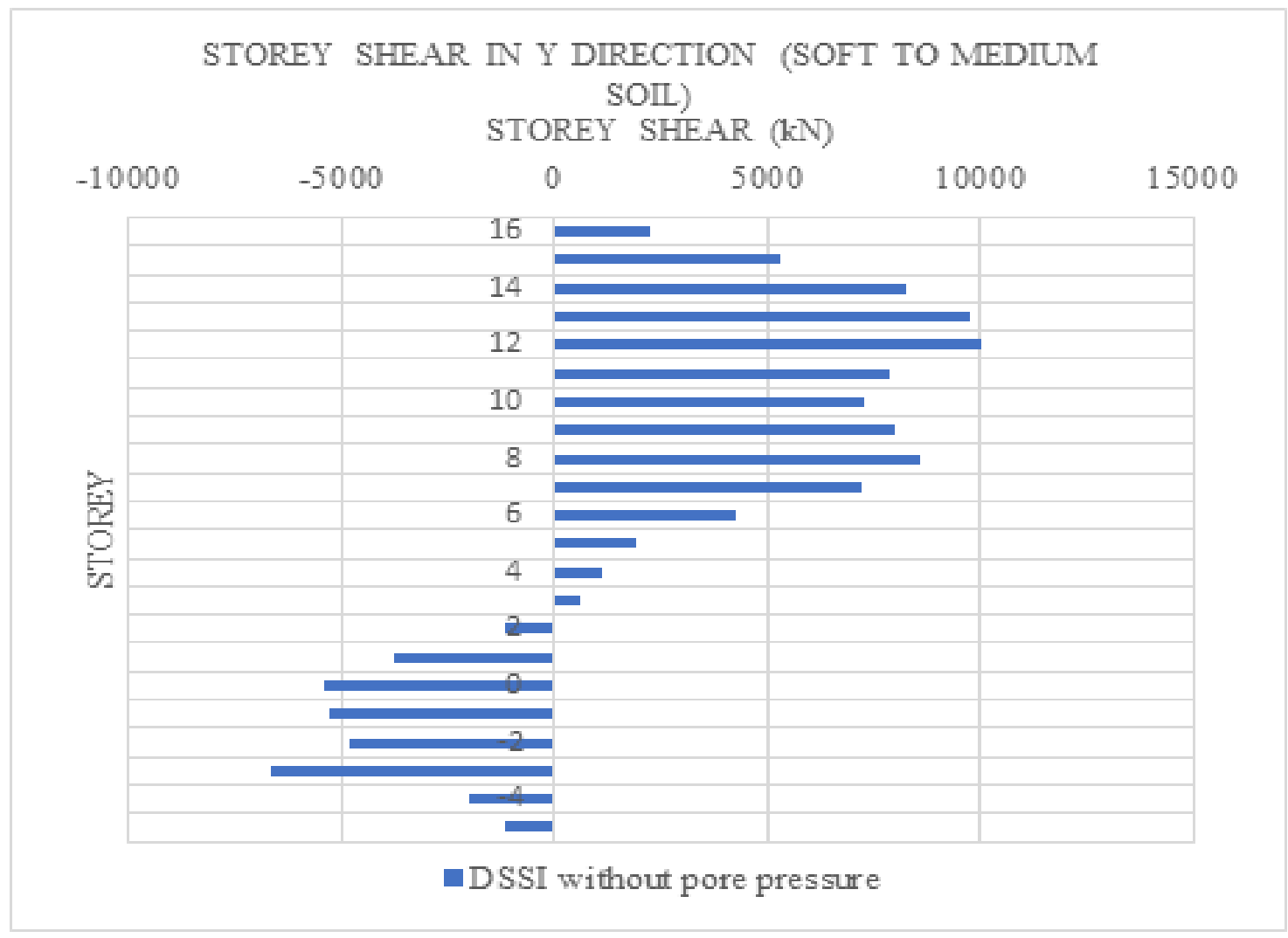

(b) STORY SHEAR (kN)

Figure 13 Storey shear for DSSI without pore pressure (a) X direction (b) Y direction (Soft to medium soil)

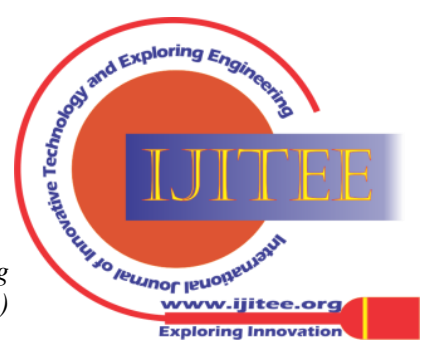




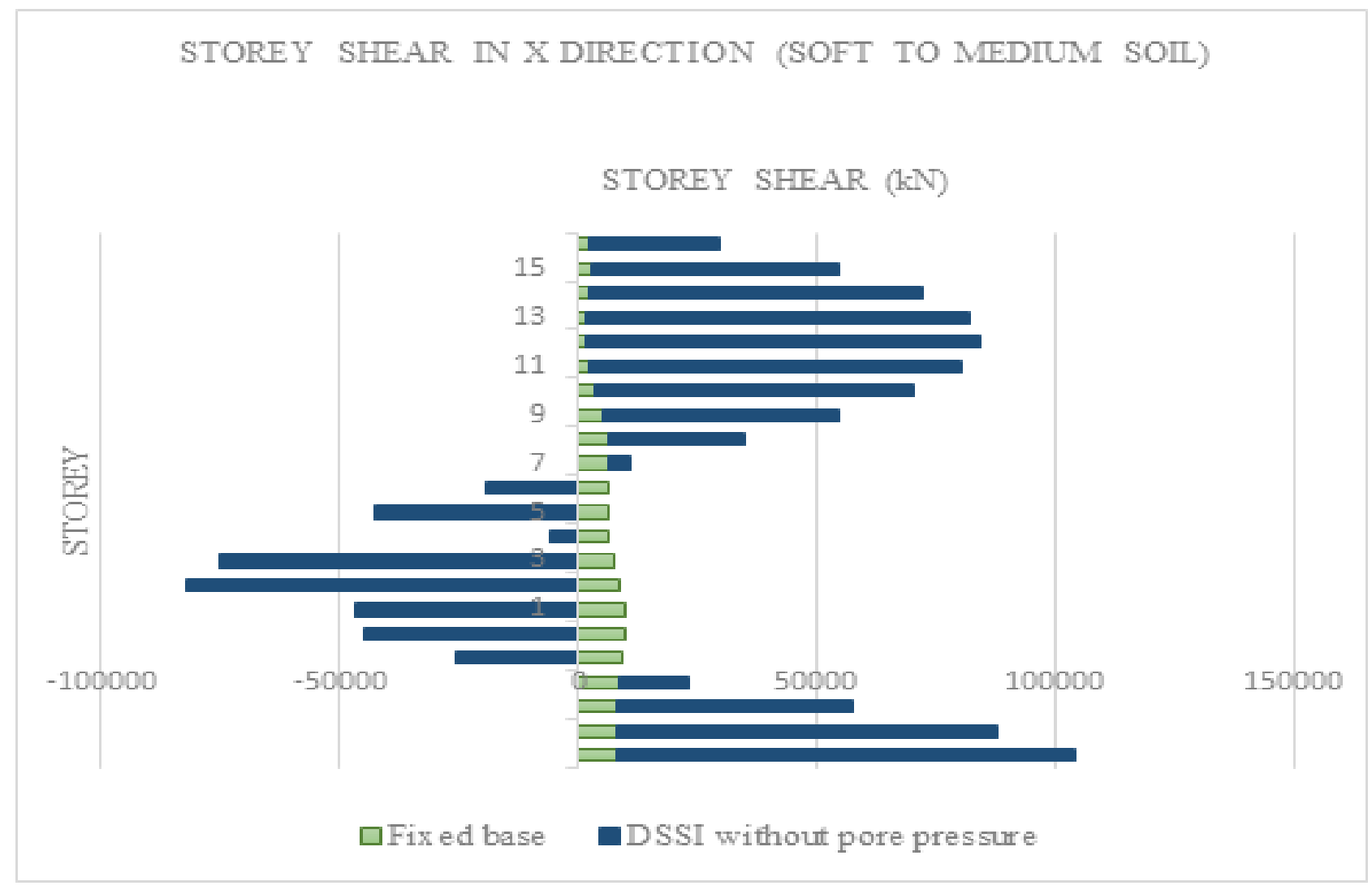

(a)

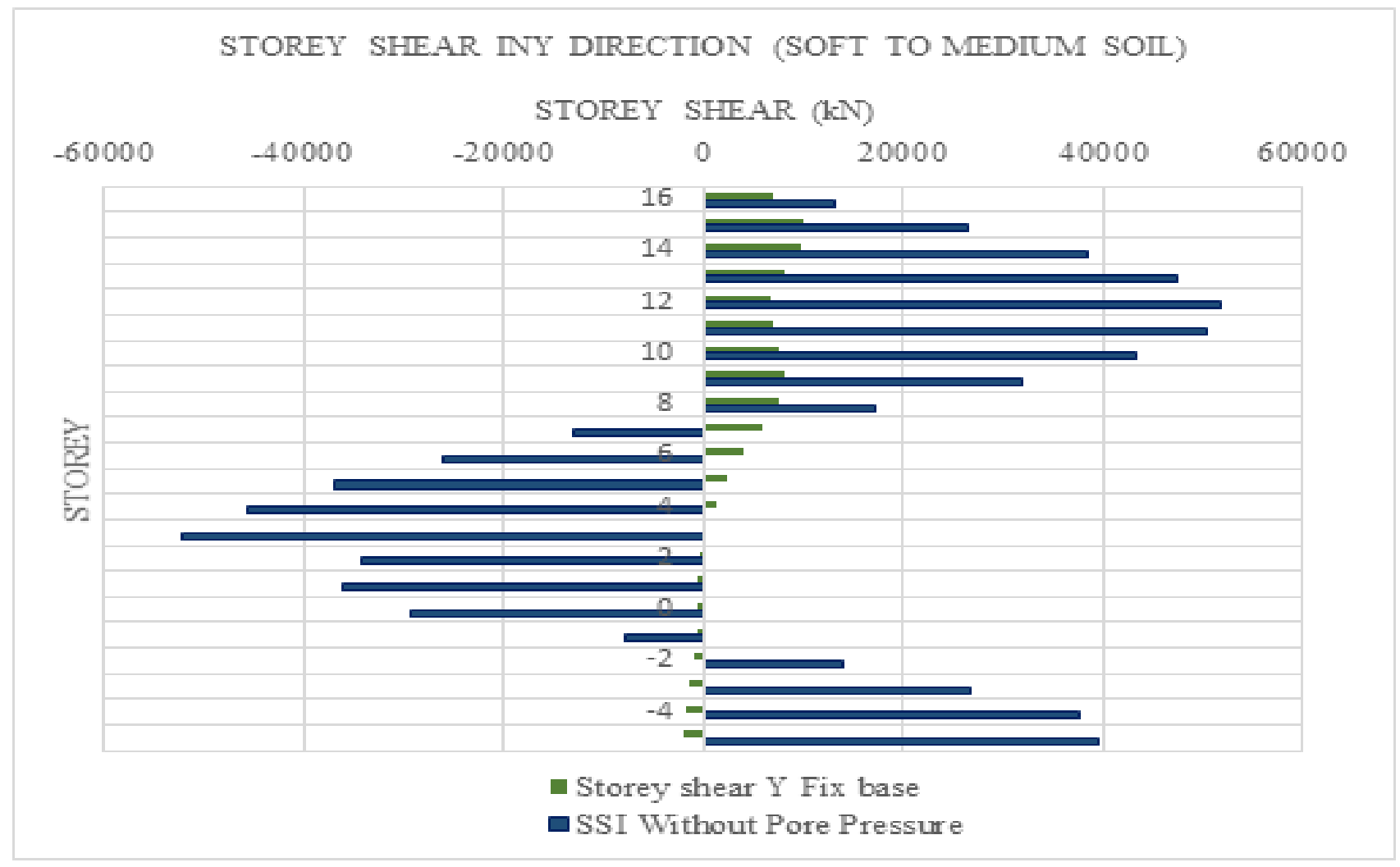

(b)

Figure 14 Comparison of Storey shear for fixed base condition with DSSI without pore pressure (a) X direction (b) Y direction (Soft to medium soil)

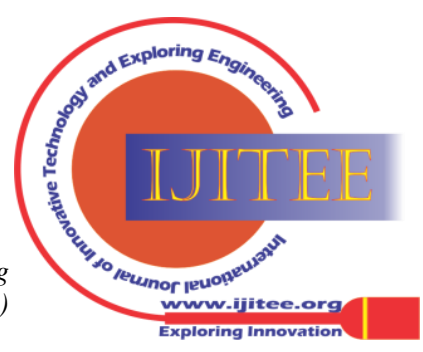


As shown in figure 8 and 9, Buildings with basements when analysed as a fixed base structure behave in its fundamental mode while the behaviour of the same building by considering dynamic soil structure interaction changes to second mode for medium to hard soil and third mode for medium to soft soil. Now the question arises is whether to consider the dynamic soil structure interaction in the analysis or not? In order to clearly understand, consider a simple lumped mass MDOF system as shown in figure 15

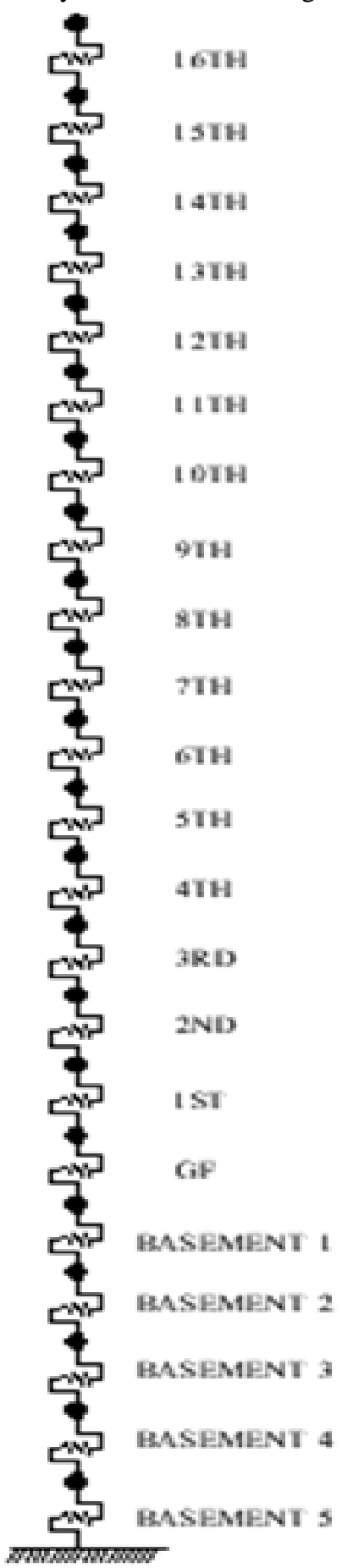

Figure 15 Lumped mass MDOF system

when the effect of DSSI is not considered the system does not get enough rigidity at base and the lumped mass of each storey deforms in the same direction. However, in actual condition there is soil around the structure which makes the substructure portion much more rigid then the super structure, thus when the effect of DSSI is considered the mass of the basement and up to 4 stories from ground level deforms in opposite direction. Therefore, it can be said that about $1 / 3$ of the building height deforms in opposite direction (second mode) with respect to fixed base condition which is shown in figure 16 below.

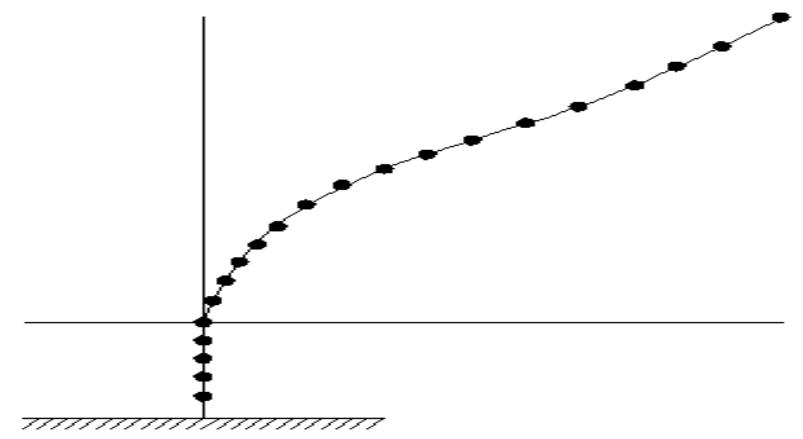

(a)

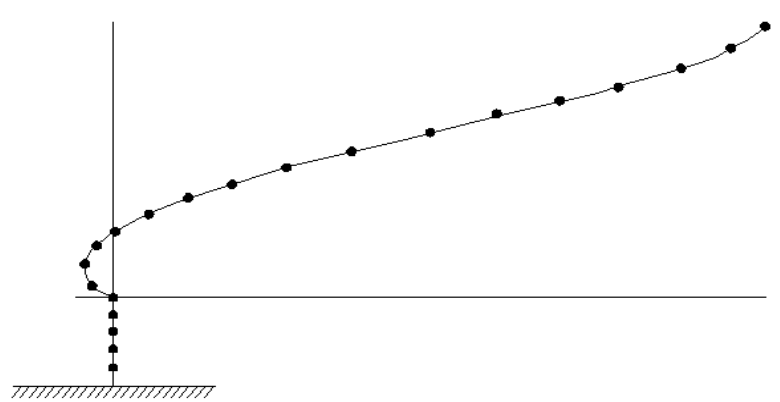

(b)

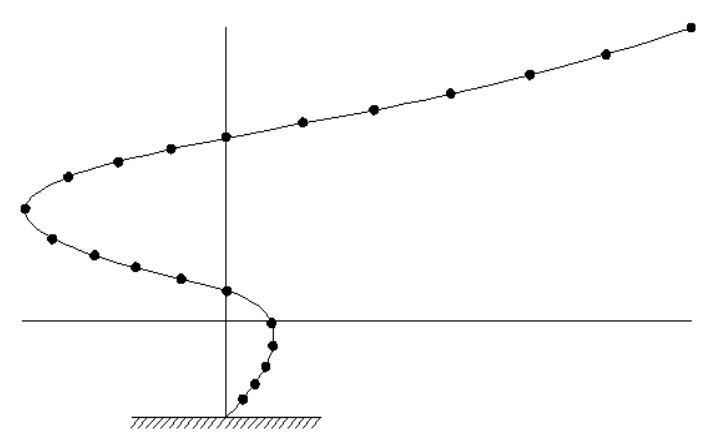

(c)

Figure 16 Behaviour of Building with basements under fixed base condition and Dynamic soil structure interaction (a) Fixed base structure (b) DSSI in medium to hard soil (c) DSSI in soft to medium soil

Therefore, it can be said that DSSI changes the failure pattern of the building and not considering DSSI in the analysis may provide unrealistic behaviour. Further, due to the flexibility of soil the maximum displacement at top storey in $\mathrm{X}$ direction increases by 1.725 times and 3.5 times for medium to hard and soft to medium soil respectively. Similarly, maximum displacement at top storey in Y direction decreases by $6 \%$ in medium to hard soil which can be said negligible while it increases by 1.80 times in soft to medium soil. From the figure 12 and 14, The maximum storey shear in X direction increased by approximately 2 times and 9.6 times for medium to hard and soft to medium soil respectively. 


\section{Performance Of Building with Basements Under Seismic Excitation Considering Soil Structure Interaction}

Similarly, the maximum storey shear in Y direction is almost similar to fixed base structure for medium to hard soil while increased by 5.3 times for soft to medium soil. The probable reason for increase in storey shear is attenuation of waves due to flexibility of soil.

Interestingly it can be said from the figure 12 and 14 that No shear reversal is observed in the fixed base structure while under medium to hard soil shear reversal occurs at $4^{\text {th }}$ storey above ground level. Similarly, shear reversal occurs at $7^{\text {th }}$ storey above ground level and at $2^{\text {nd }}$ basement level for soft to medium soil. The shear reversal occurs at two locations due to the third mode response of the building under soft to medium soil.

B. Effect of pore pressure: -

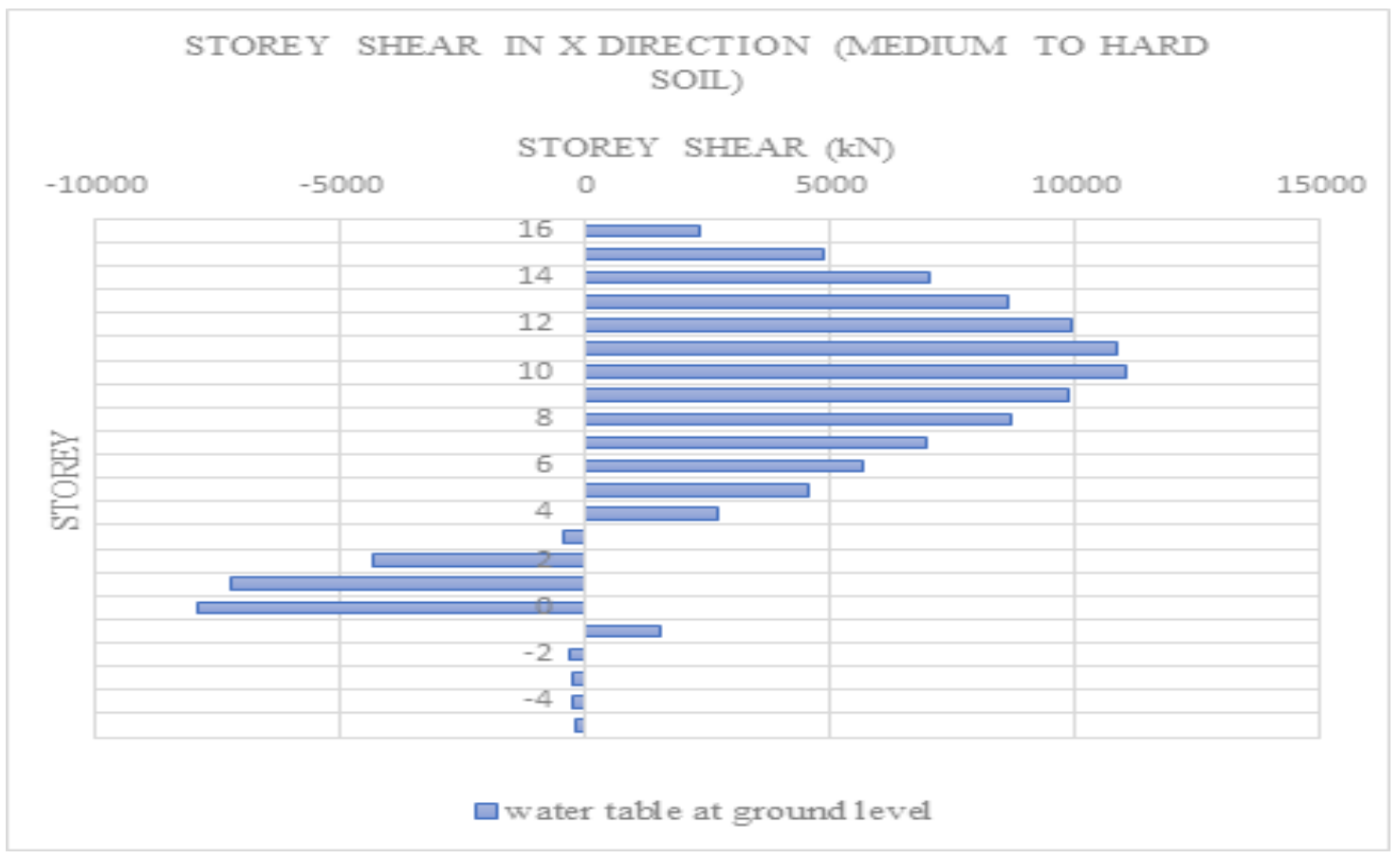

(a)

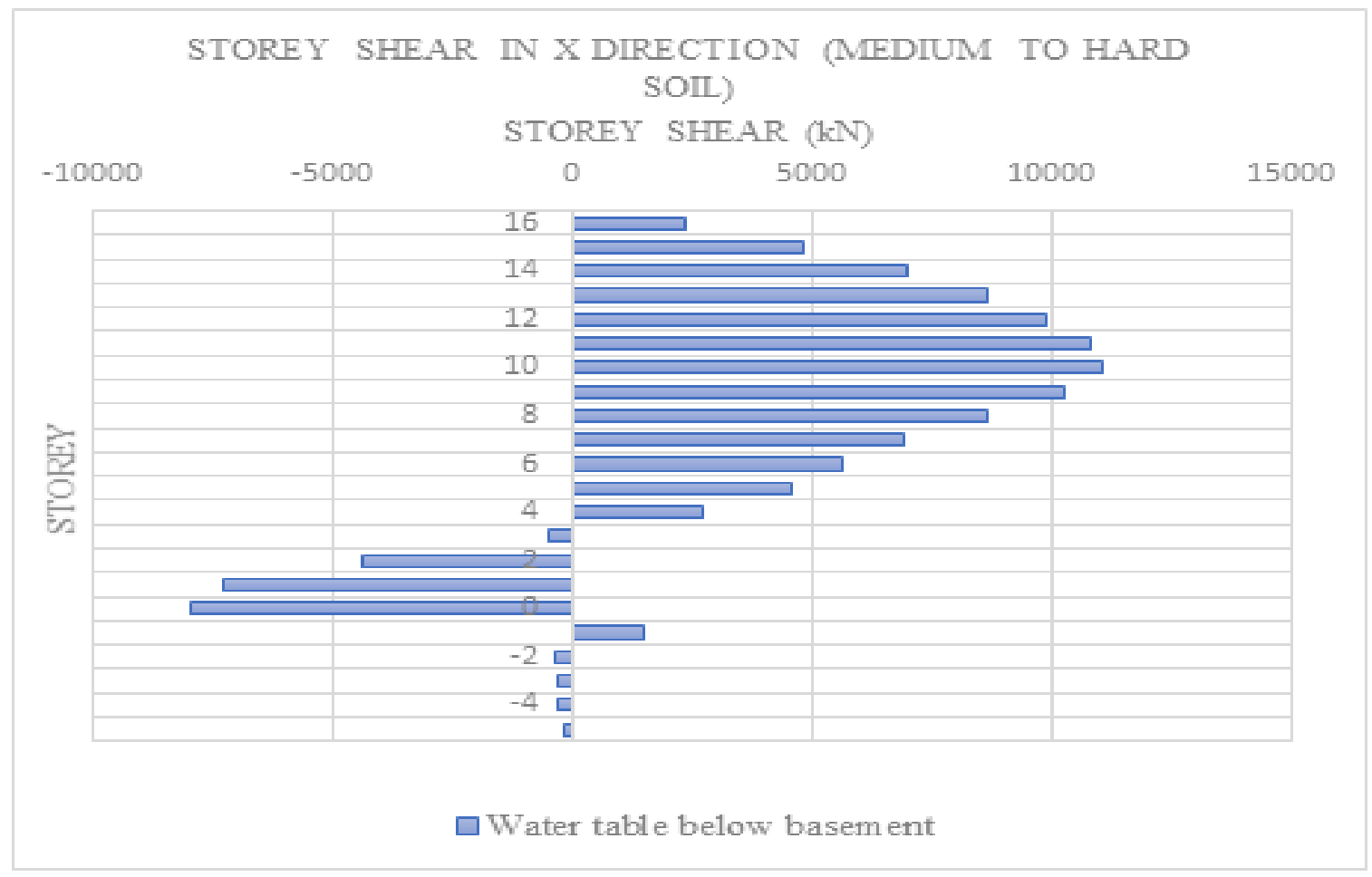

(b)

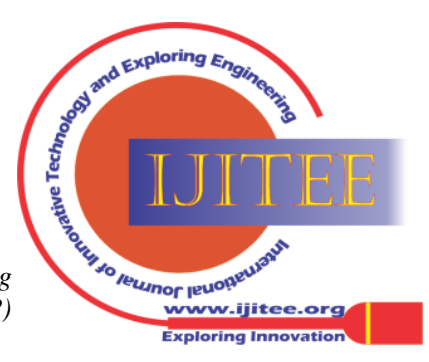




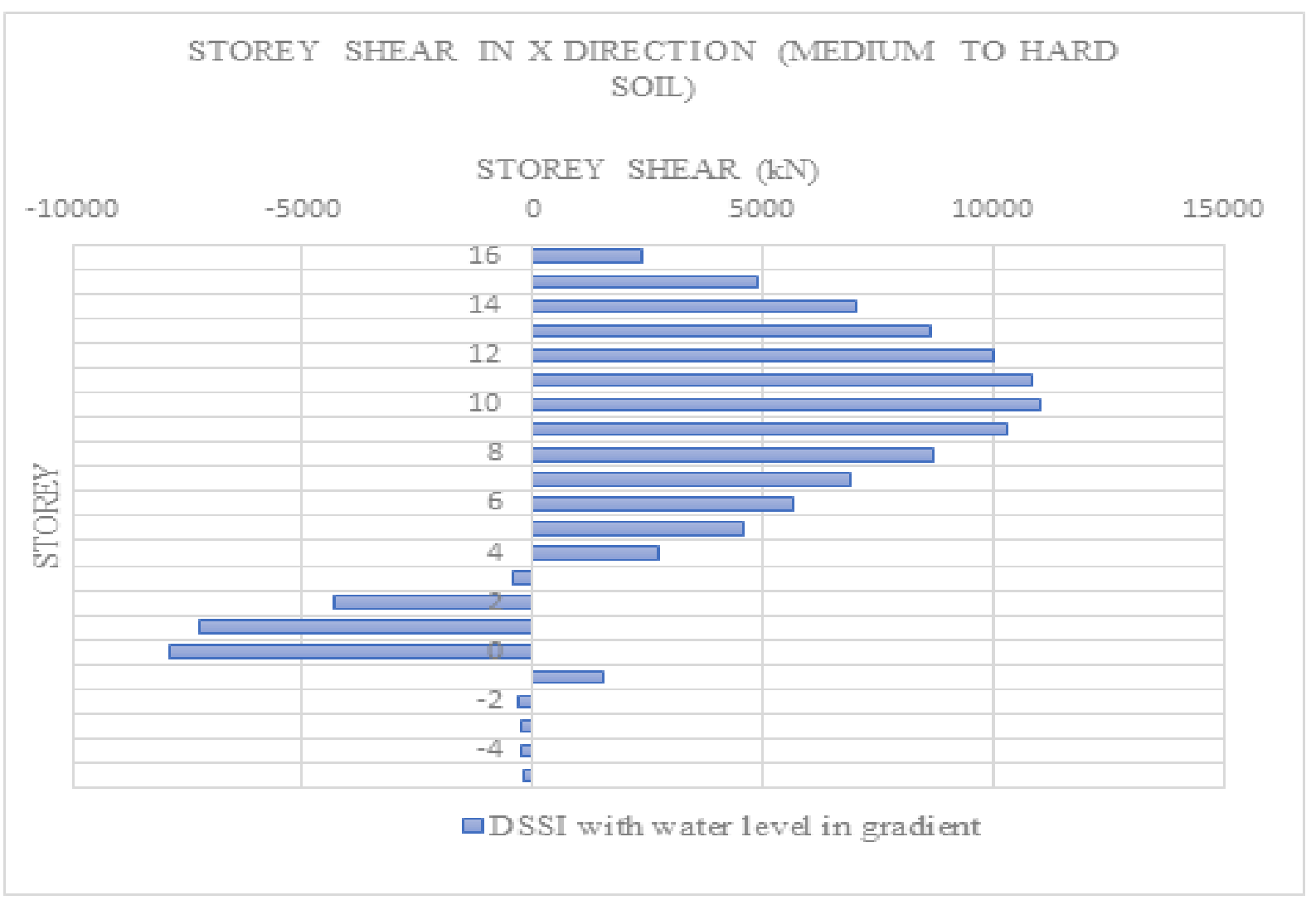

(C)

Figure 17 Storey shear in horizontal $X$ direction (a) water table at ground level (b) water table below basement (c) water level in gradient (Medium to hard soil)

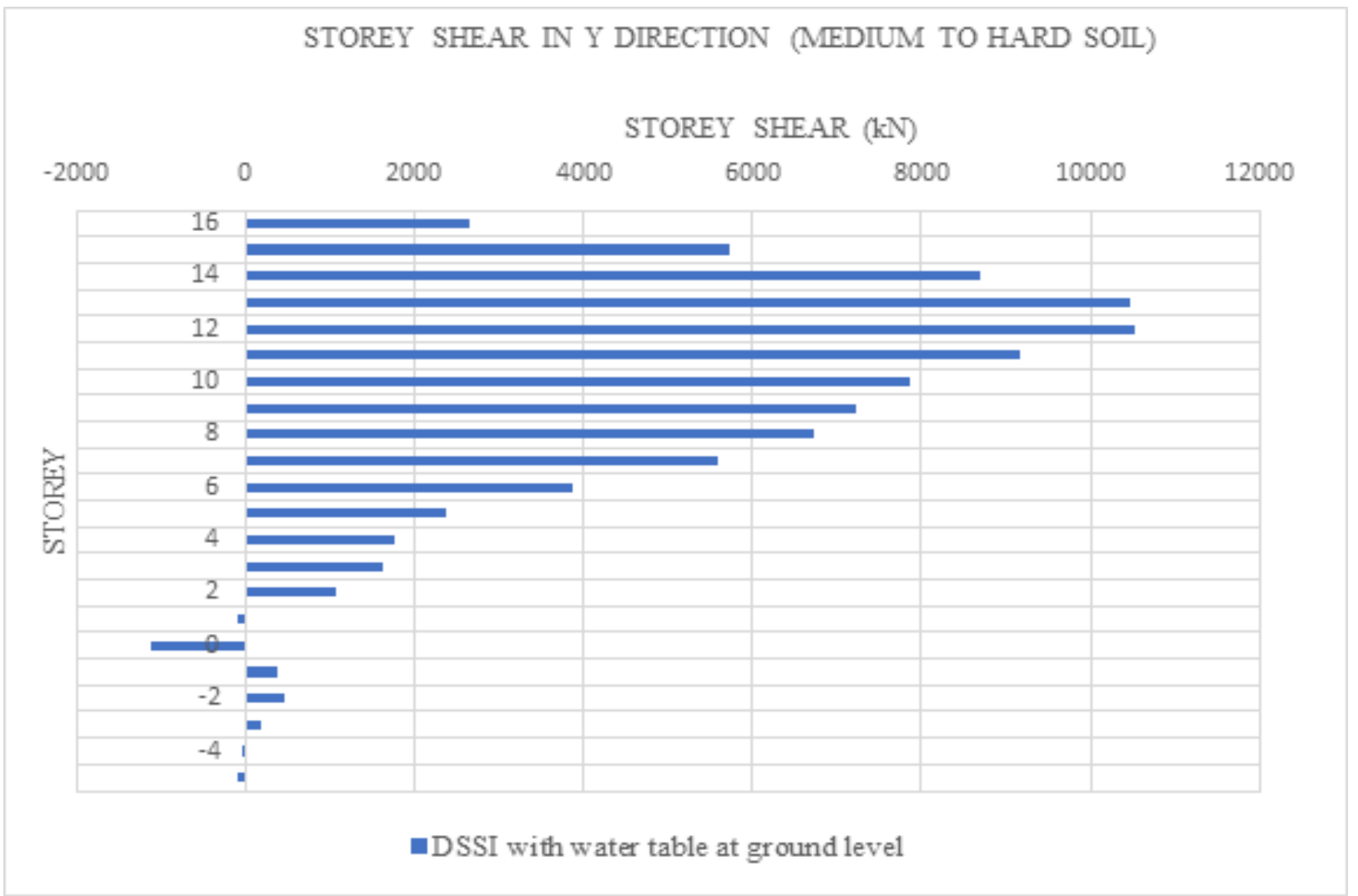

(a)

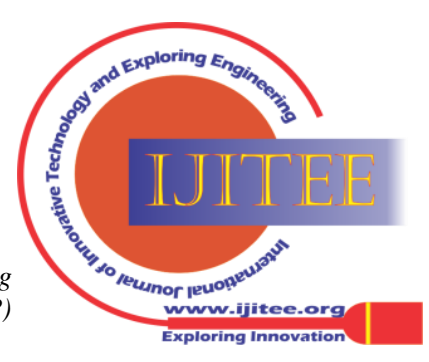


Performance Of Building with Basements Under Seismic Excitation Considering Soil Structure Interaction

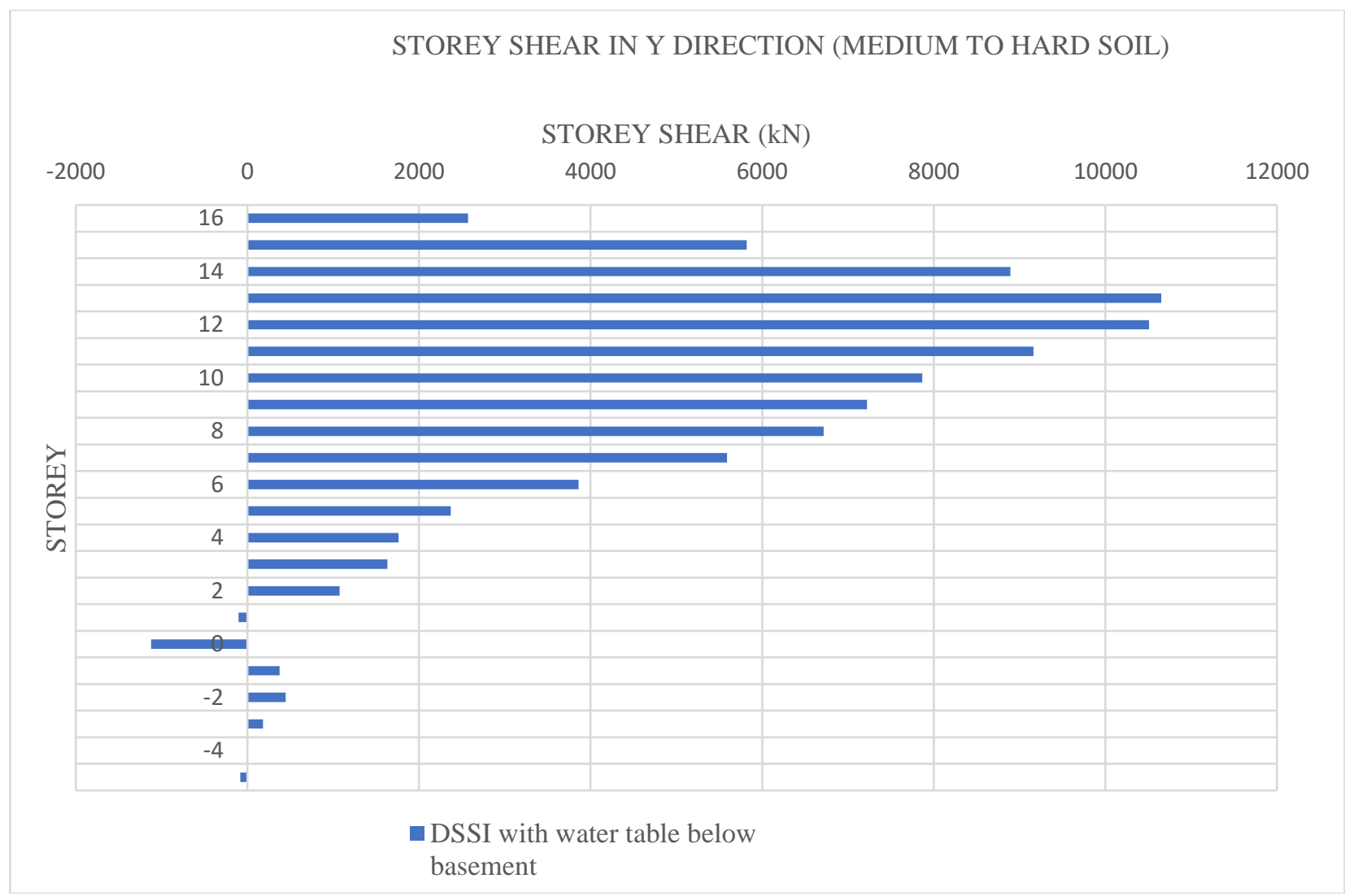

(b)

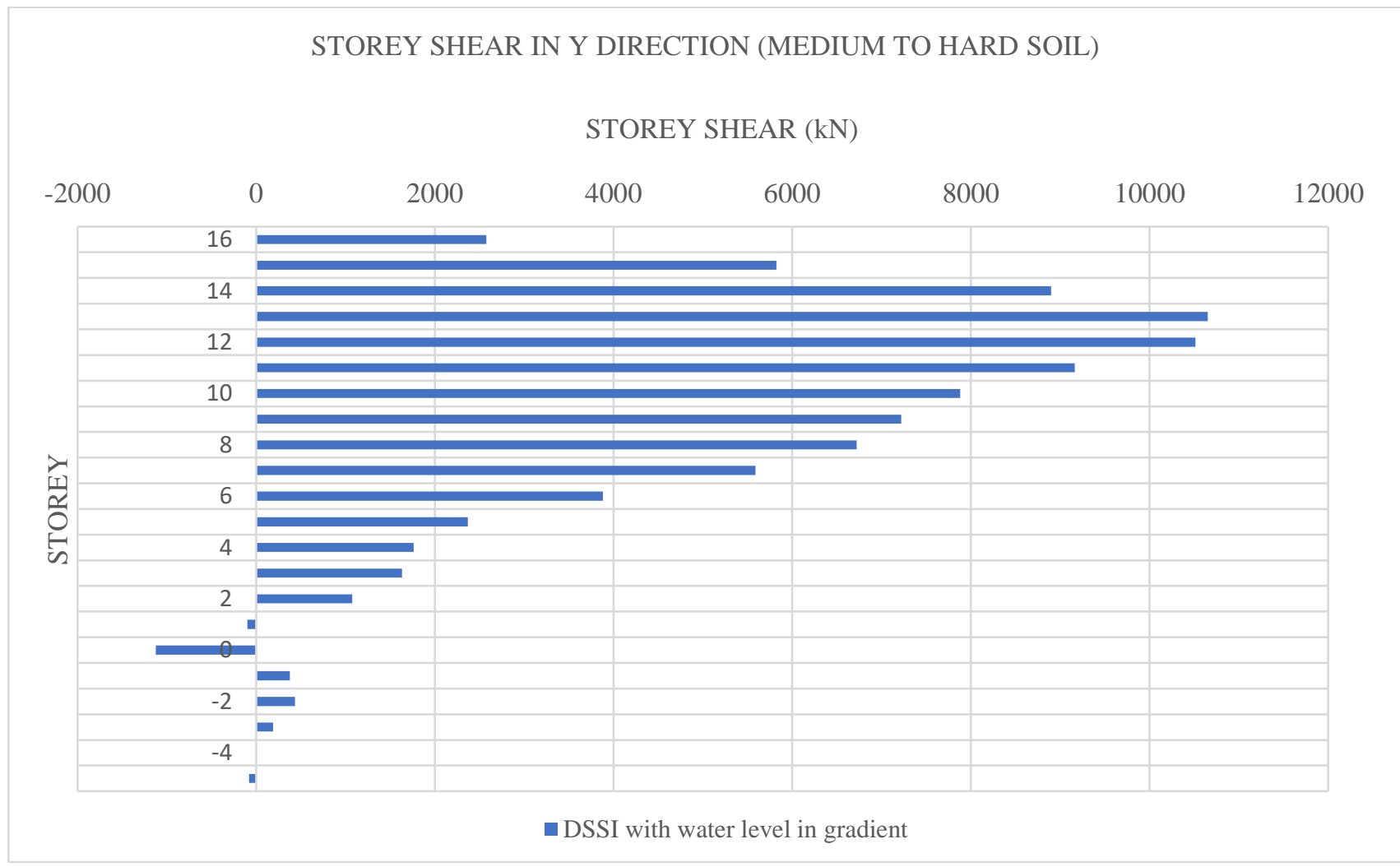

(c)

Figure 18 Storey shear in horizontal Y direction (a) water table at ground level (b) water table below basement (c) water level in gradient (Medium to hard soil)

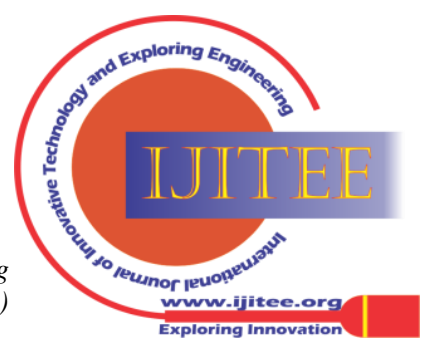




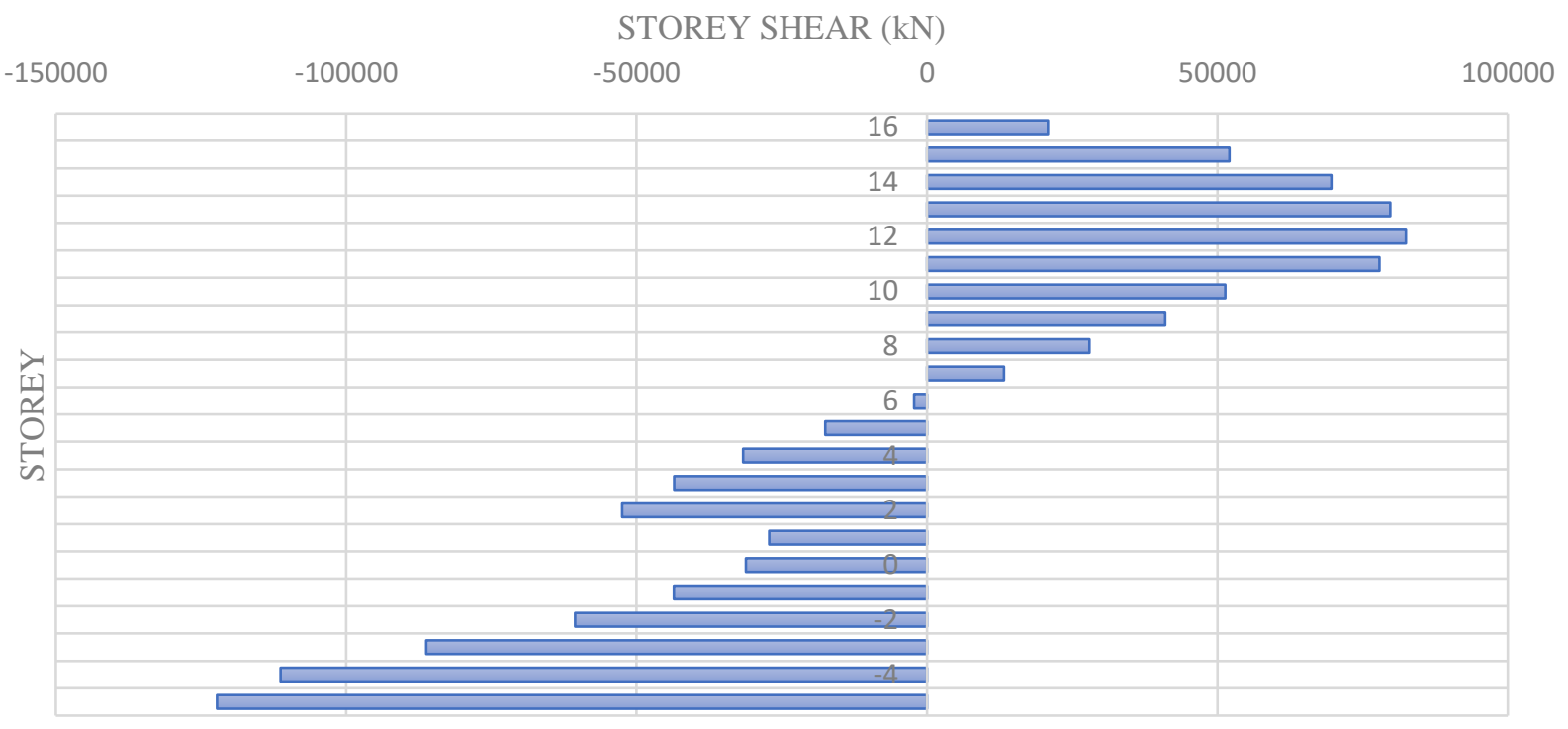

(a)

\section{STOREY SHEAR IN Y DIRECTION (SOFT TO MEDIUM SOIL)}

STOREY SHEAR $(\mathrm{kN})$

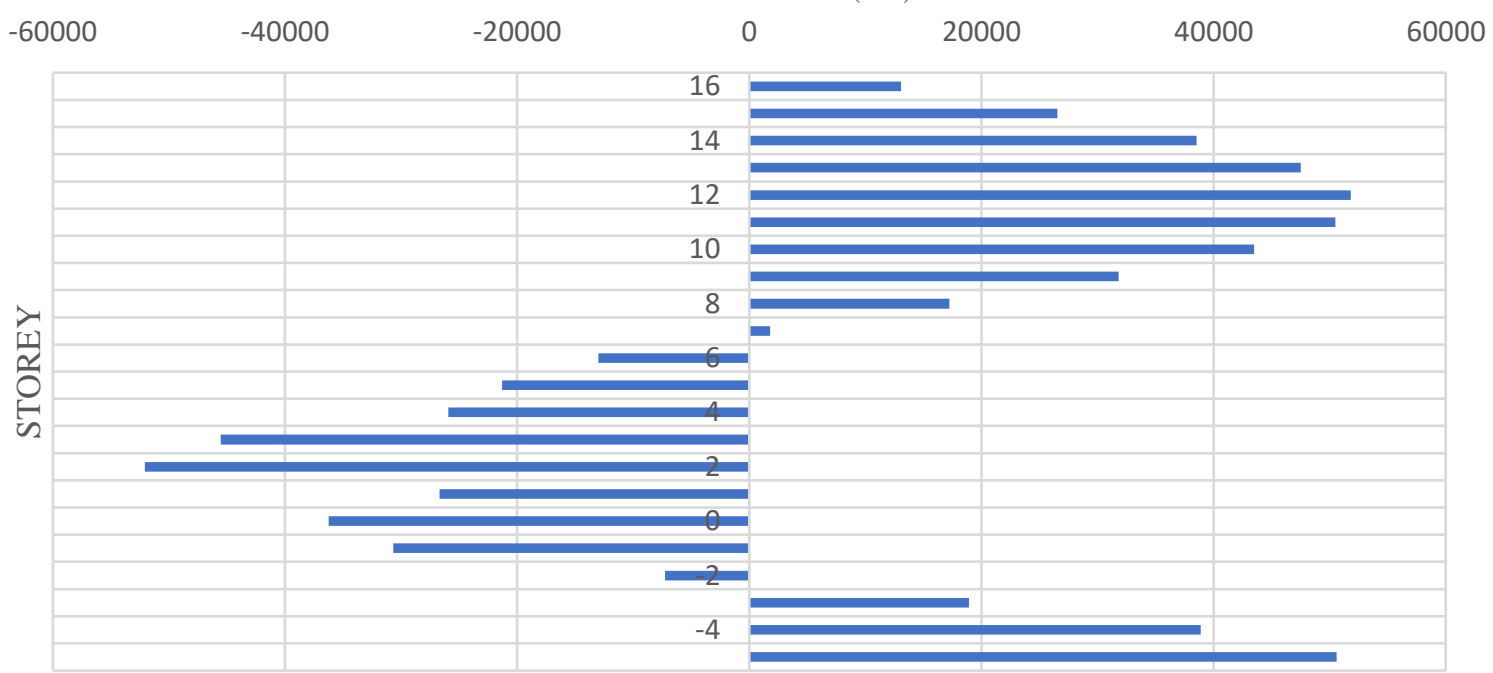

- DSSI with water level in gradient

\section{(b)}

Figure 19 Storey shear for DSSI with water level in gradient (a) X direction (b) Y direction (Soft to medium soil)

From the figure $8,9,17,18$, it is observed that The pore pressure generated on soil due to presence of water level mostly affects the structure only under availability of gradient and therefore it becomes the worst case. During seismic excitation, presence of pore pressure at both the side benefits the structure and due to that reason storey shear for soft to medium soil is shown for worst case only (figure 19). From the figure 8 (a), The maximum displacement at top storey in $\mathrm{X}$ direction under the worst case of pore pressure for medium to hard soil increases by 1.12 times in comparison with fixed base structure while decreases by $4 \%$ with respect to the condition where pore pressure around the basement is absent. The decrease in displacement due to the presence of pore pressure is due to the fact that pore pressure is applied in the $+\mathrm{X}$ direction and the basement deflects in $-\mathrm{X}$ direction thereby resists the displacement and benefits the structure. 
While for soft to medium soil, it is visible from the figure 9 (a), that the maximum displacement at top storey in $\mathrm{X}$ direction under the worst case of pore pressure increases by 3.5 times in comparison with fixed base structure while increases by $1 \%$ with respect to the condition where pore pressure around the basement is absent.

Similarly, it is seen from figure 8 (b), that the maximum displacement at top storey in $\mathrm{Y}$ direction under the worst case of pore pressure decreases by $6 \%$ in comparison with fixed base structure while increases by 1.04 times with respect to the condition where pore pressure around the basement is absent. The increase in displacement due to the presence of pore pressure is due to the fact that pore pressure is applied in the $+Y$ direction and the basements also deflects in $+Y$ direction thereby causing additional displacement. While for soft to medium soil, it is visible from the figure 9 (b), that the maximum displacement at top storey in Y direction under the worst case of pore pressure increases by 1.75 times in comparison with fixed base structure while increases by $3.9 \%$ with respect to the condition where pore pressure around the basement is absent.

The results of storey shear in figure 17,18,19 shows that The presence of water around the basement reduces the storey shear in the basement stories by about 13 times in both direction as it is evident from the Pascal's law which states that "pressure at a point in a fluid is equal in all direction". Therefore, it can be said that presence of water around the basement is beneficial during earthquake.

Moreover, pore pressure causes uplift of foundation, therefore suitable arrangements like pressure relief valves and/or imposing additional weight to control the uplift is recommended where the permanent ground water level is high.

\section{Effect of reducing the rigidity of basement}

In order to determine the effect of rigidity, the number of basements were reduced to three and the discussion is summarised in this section As it is observed that rigidity of basement in presence of soil affects the above ground structure, an analysis for building with three basements indicates that the behaviour of building does not change in both type of soil i.e. second mode and third behaviour is observed even for three basements under medium to hard and soft to medium soil respectively.

By reducing number of basements, the maximum displacement at top storey in $\mathrm{X}$ direction increases by 1.10 times and 3.3 times for medium to hard and soft to medium soil respectively. Similarly, maximum displacement at top storey in Y direction decreases by $3 \%$ in medium to hard soil which can be said negligible while it increases by 2.10 times in soft to medium soil. The maximum storey shear in $\mathrm{X}$ direction increased by approximately 1.10 times and 8.2 times for medium to hard and soft to medium soil respectively. Similarly, the maximum storey shear in $\mathrm{Y}$ direction is almost similar to fixed base structure for medium to hard soil while increased by 5.3 times for soft to medium soil. The probable reason for increase in displacement and storey shear is attenuation of waves due to flexibility of soil. By reducing number of basements to three, the maximum displacement at top storey in $\mathrm{X}$ direction gets reduced by 36 $\%$ and $5 \%$ for medium to hard soil and soft to medium soil respectively with respect to five basements. Similarly, maximum displacement at top storey in Y direction decreases by $3 \%$ in medium to hard soil which can be said negligible while it increases by $16 \%$ in soft to medium soil with respect to five basements.

The storey shear in $\mathrm{X}$ direction for the same building with three basements gets reduced by $45 \%$ and $14.5 \%$ in medium to hard soil and soft to medium soil respectively with respect to five basements while the storey shear in $\mathrm{Y}$ direction is approximately same in both the buildings namely building with five basements and building with three basements.

Therefore, if there is a choice between providing three basements or more than three basements, providing three basements gives significant reduction in displacement and storey shear for medium to hard soil while providing five basements or three basements in soft soil has little effect from the design point of view.

\section{Effect on natural time period of structure: -}

\section{Table 6 Time period}

\begin{tabular}{|c|r|l|l|}
\hline Condition & fixed base & $\begin{array}{l}\text { Medium to } \\
\text { hard soil }\end{array}$ & $\begin{array}{l}\text { Soft to } \\
\text { medium soil }\end{array}$ \\
\hline $\begin{array}{c}\text { Time } \\
\text { period(sec) }\end{array}$ & 3.93 & 3.83 & 4.1 \\
\hline
\end{tabular}

To determine the effect on natural time period, modal analysis is performed by Ritz vector and It is observed that the building with basement have negligible effect on time period, as the basement will undergo rigid body motion.

\section{CONCLUSION}

In present study, performance of building with multiple basements under seismic excitation is investigated. The three-dimensional analysis is performed for a seventeen story $\mathrm{RC}$ moment frame-structural wall system having five and three basements. The buildings were assumed to be founded on two types of layered soil namely medium to hard and soft to medium soil. The dynamic analysis is performed in SAP 2000 by using nonlinear direct integration time history analysis under Bhuj earthquake. Upon studying several general cases like dynamic soil structure interaction without pore pressure, dynamic soil structure interaction with water level at ground level, water level below basement, water level having gradient around the structure and comparing their results with fixed base structure following major conclusions are drawn: -

- Influence zone for performing dynamic soil structure interaction can be taken as five times the width of building in the direction considered. However, the depth of influence zone is to be decided by performing sensitivity analysis in a way that time period of entire soil structure system gets constant after that particular depth.

- Buildings with basements when analysed as a fixed base structure behave in its fundamental mode while the behaviour of the same building by considering dynamic soil structure interaction changes to second mode for medium to hard soil and third mode for medium to soft soil thereby changing the failure pattern of the structure.

Published By:

Blue Eyes Intelligence Engineering and Sciences Publication (BEIESP) (C) Copyright: All rights reserved.

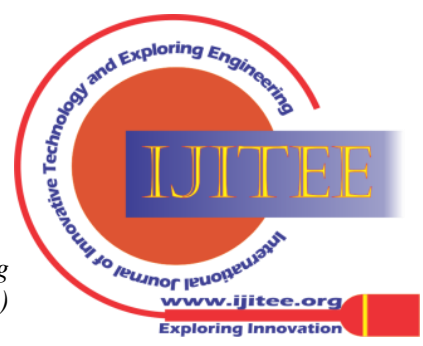


- It is found that the lateral displacement has shown a considerable increase ranging from 1.10 times to 3.50 times and the maximum storey shear also increased by 1.10 times to 9.60 times depending upon type of soil in comparison with the fixed based structure.

- In presence of soil the change in behaviour pattern of building leads to shear reversal at $4^{\text {th }}$ storey above ground level for medium to hard soil. Similarly, shear reversal occurs at $7^{\text {th }}$ storey above ground level and at $2^{\text {nd }}$ basement level for soft to medium soil which represents the third mode behaviour.

- Among all the cases studied, the worst case observed for maximum displacement and storey shear is dynamic soil structure interaction without pore pressure. Further, it is observed that presence of pore pressure on both side of the basement benefits the structural response and reduces the storey shear in the basement part.

- Interestingly, even after reducing the numbers of basements to three the behaviour of the building is found to be similar to five basements. However, there is considerable decrease of $36 \%$ and $45 \%$ lateral displacement and storey shear respectively in the rigid direction of the building.

\section{Based on above conclusion following recommendations are made: -}

- Dynamic soil structure interaction effect is not beneficial for building with basements and not considering it may lead to unrealistic results. Therefore, it is recommended to perform dynamic soil structure interaction for all the tall building with multiple basements resting on soft to medium soil and for important buildings resting on medium to hard soil.

- It is recommended to perform dynamic soil structure interaction by neglecting the inertial effect of pore pressure. However, if it is proved by geotechnical consultants that permanent water will be found at a particular level then the benefit of pore pressure can be taken into account for the permanent water level only.

- If there is a choice between providing three basements or more than three basements, it is recommended to provide three number of basements.

The conclusions and recommendations of the present study can be considered in the analysis and design of similar type of structure resting on similar layered soil with proper engineering judgement.

\section{REFERENCES}

1. E. H. Ganainy and H. M. Naggar, "Seismic performance of three-dimensional frame structures with underground stories," Soil Dynamics and Earthquake Engineering, vol. 29, pp. 1249-1261, 2009.

2. B. R. Jayalekshmi and H. K. Chinmayi, "Effect of soil stiffness on seismic response of reinforced concrete buildings with shear walls," Innovative Infrastructure solutions, 2016.

3. H. R. S. Tabatabaiefar, B. Fatahi and B. Samali, "Seismic Behaviour of Building Frames Considering Dynamic Soil-Structure Interaction," International Journal of Geomechanics, vol. 13, pp. 409-420, 2013.

4. M. Tehranizadeh and M. S. Barkhordari, "Effect of Peripheral Wall openings in Basement and Number of Basement Floors on the Base level of Braced Framed Tube System," International Journal of Civil Engineering, 2017.

5. R. Scarfone, R. Conti and M. Morigi, "Assessment of dynamic soil-structure interaction effects for tall buildings: A 3D numerical approach," Soil Dynamics and Earthquake Engineerng, vol. 128, 2020.

6. Z. Haiyang, Y. Jing, F. Jisai and C. Guoxin, "Seismic performance of underground subway station considering connection modes and

Published By:

Blue Eyes Intelligence Engineering and Sciences Publication (BEIESP)

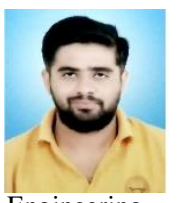

Toshif A. Patel, completed his B.E in civil engineering from BVM engineering college Anand, Gujarat. Presently, He is working as Structural designer at Vrajlal V. Ambalia Consulting Structural Designer. His research area includes Soil Structure interaction, Structural Dynamics, Machine foundation, Earthquake

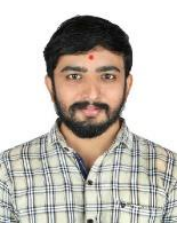

Ravi R. Karkar, completed his B.E in civil engineering from Sarvajanik college of Engineering and technology, Gujarat. Presently, He is working as Structural designer at Vrajlal V. Ambalia Consulting Structural Designer. His research area includes Soil Structure interaction, Structural Dynamics, design of tall structure, steel structure.

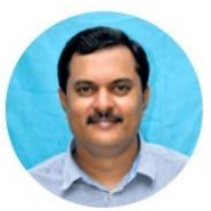

Dr. Jigar K Sevalia, holds a $\mathrm{PhD}$ in Structural engineering from Saradar Vallabhbhai National institute of Technology (SVNIT), Surat- Gujarat. Currently, $\mathrm{He}$ is Professor and Head of the Civil Engineering Department at Sarvajanik college of Engineering and technology, Gujarat. He has published Numbers of Research paper in International Journals. His research area includes Structural Engineering, Structural Dynamics, Machine Foundations, Concrete Technology, Earthquake Engineering, Repair-Rehabilitation-Retrofitting of Structures.

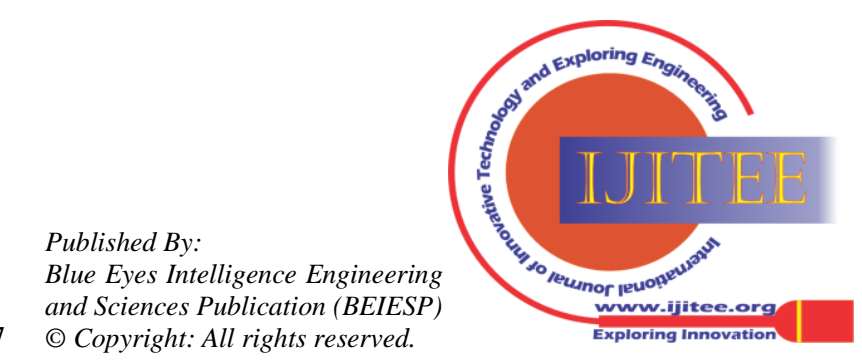

